\title{
AN INVESTIGATION OF AUTOMATIC GENERATION CONTROL FOR AN ISOLATED POWER SYSTEM
}

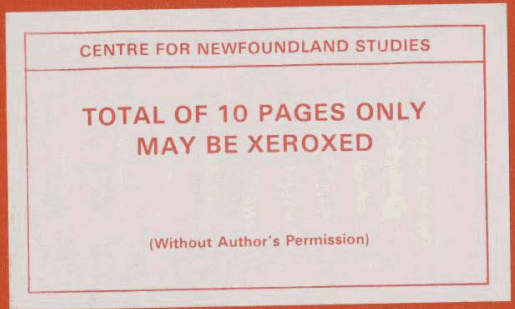

GLENN V. HICKS 


The author has granted a nonexclusive licence allowing the National Library of Canada to reproduce, loan, distribute or sell copies of this thesis in microform, paper or electronic formats.

The author retains ownership of the copyright in this thesis. Neither the thesis nor substantial extracts from it may be printed or otherwise reproduced without the author's permission.
L'auteur a accordé une licence non exclusive permettant à la Bibliothèque nationale du Canada de reproduire, prêter, distribuer ou vendre des copies de cette thə̀se sous la forme de microfiche/film, de reproduction sur papier ou sur format électronique.

L'auteur conserve la propriété du droit d'auteur qui protège cette thèse. $\mathrm{Ni}$ la thèse ni des extraits substantiels de celle-ci ne doivent être imprimés ou autrement reproduits sans son autorisation. 


\section{An Investigation of Automatic Generation Control for an Isolated Power System}

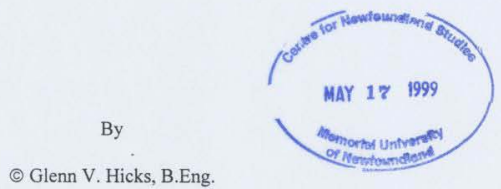

A thesis submitted to the School of Graduate Studies in partial fulfillment of the requirements for the degree of Master of Engineering

Faculty of Engineering and Applied Science Memorial University of Newfoundland September 1997 


\section{Abstract}

For the Newfoundland and Labrador Hydro (NLH) Energy Management System, the Automatic Generation Control (AGC) process performs the task of adjusting system generation to meet the load demand and of regulating the large system frequency changes. A result of the mismatches between system load and system generation, and system frequency and the desired value of $60 \mathrm{~Hz}$ is the accumulation of time error. Present AGC schemes used to combat this problem utilize a static, linear system response characteristic (SRC) to model the actual variable, non-linear system response to frequency deviations. For interconnected power systems, the AGC control signal is determined from the sum of the tie-line power interchange between interconnected systems and the system frequency deviation weighted by a bias factor, which is the SRC approximation. For an isolated power system, such as the NLH system, the control signal relies entirely on the weighted frequency deviation. Thus, the approximation of the SRC becomes increasingly important in the AGC process of an isolated power system.

Current industry practice is to select the AGC bias factor based on the SRC and the annual peak load. This bias value then remains constant throughout the year. The use of a variable or dynamic value that is continuously changing throughout the year based on the system load and on-line generation can better approximate the SRC, and result in improved frequency regulation. Past research in this area has focused on the use of a variable bias factor in the AGC process of interconnected power systems. In this thesis, various methods for the calculation of a variable bias factor for use in an isolated power 
system are presented. Results show that by varying the bias factor in response to changes to the on-line generation (megawatt output and network configuration), improved frequency regulation, and hence a decrease in accumulated time error, can be realized.

This thesis presents an investigation of the Automatic Generation Control process for an isolated power system. Using computer simulation techniques, a detailed model of the NLH Power system was implemented and tested using the load demand as input. The effect of a variable bias factor was investigated for various operating conditions, and compared to the presently used static value. Based on a set of performance indices, including the accumulated time and unit control errors, a control scheme was determined that provided improved frequency regulation in an isolated power system. 


\section{Acknowledgments}

This research was jointly funded by Newfoundland and Labrador Hydro and the Faculty of Engineering and Applied Science, Memorial University of Newfoundland through the Power System Scholarship. The author is indebted to both parties for the financial support provided during the course of this research.

I would like to express my most sincere thanks to Dr. Benjamin Jeyasurya of the Faculty of Engineering and Applied Science for sharing his valuable knowledge in the area of power systems and for his guidance throughout all stages of my research work. Also, I would like to thank Mr. Bill Snow of Newfoundland and Labrador Hydro for providing the resources and practical experience with regards to AGC.

I acknowledge the assistance received from faculty members, fellow graduate students and the other staff of the Faculty of Engineering and Applied Science.

Finally, I express my sincere gratitude to my family and friends for their encouragement, support and understanding, without which this research work would not have been possible. 


\section{Table of Contents}

$\begin{array}{lll}\text { Abstract } & \text { ii }\end{array}$

Acknowledgments

iv

Table of Contents

v

List of Figures

viii

List of Tables

x

Nomenclature

xi

Chapter 1 - Introduction

1.1 Aim of Thesis

1.2 Thesis Organization

Chapter 2 - Automatic Generation Coutrol in Power Systems

2.1 Introduction

5

2.2 Power System Equipment Characteristics and Modelling

2.3 Automatic Generation Control Fundamentals 


\section{List of Figures}

Figure 2.1 Basic power system control structure..................................................... 7

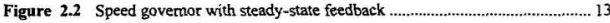

Figure 2.3 Ideal steady-state characteristics of a governor with speed droop ….......... 15

Figure 2.4 Effect of speed-changer setting on governor characteristic ..................... 16

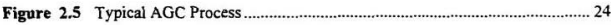

Figure 3.1 Single Hydro Generator with Primary Control Only .............................. 33

Figure 3.2 Output Data for Single Machine Model with Primary Control Only ......... 33

Figure 3.3 Single Hydro Generator with Primary and Secondary Control................... 34

Figure 3.4 Simulation Data for Single Machine System with $B=25$ pu MW/0.1 Hz ... 35

Figure 3.5 Decrease in Bias Factor for the Single Machine System .......................... 36

Figure 3.6 Increase in Bias Factor for the Single Machine Systern ........................... 36

Figure 3.7 Multi-Machine Power System Model ............................................. 37

Figure 3.8 Simulation Data for Multi-Machine Systern with $B=25$ pu MW:J.1 Hz .... 38

Figure 3.9 Decrease in Bias Factor for the Multi-Machine System .......................... 39

Figure 3.10 Increase in Bias Factor for the Multi-Machine System ..............................40

Figure 3.11 Overall NLH Power System Model …..................................................4

Figure 3.12 General Model for Turbine Systems ................................................. 45

Figure 3.13 Thermal Generating Unit Model ....................................................... 47

Figure 3.14 Governor, Pressure and Fuel Dynamics for the Thermal Generating Unit. 47

Figure 3.15 Steam Turbine Dynamics for the Thermal Generating Unit ..................... 48

Figure 3.16 Hydro Generating Unit Model .............................................................. 48 
Figure 3.17 Gas Turbine Generating Unit Model 48

Figure 3.18 Unit Controller and Load Reference Actuator Model. 49

Figure 3.19 Automatic Generation Control Model. 50

Figure 5.1 Load Profile for October 17, 1996 60

Figure 5.2 Dynamic Bias Factors for October 17, 1996 61

Figure 5.3 Time Error for October 17, 1996 62

Figure 5.4 Mean UCE Sum for October 17, 1996 62

Figure 5.5 Load Profile for April 4, 1997. 63

Figure 5.6 Dynamic Bias Factors for April 4, 1997 63

Figure 5.7 Time Error for April 4, 1997 64

Figure 5.8 Mean UCE Sum for April 4, 1997 . 64

Figure 5.9 Load Profile for June 26, 1997. 65

Figure 5.10 Dynamic Bias Factors for June 26, 1997 65

Figure 5.11 Time Error for June 26, 1997 66

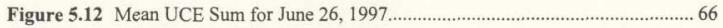

Figure 5.13 Load Profile for July 11, 1997 67

Figure 5.14 Dynamic Bias Factors for July 11, 1997 67

Figure 5.15 Time Error for July 11, 1997. 68

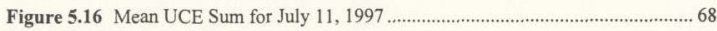

Figure 5.17 Load Profile for July 12, 1997 69

Figure 5.18 Dynamic Bias Factors for July 12, 1997 69

Figure 5.19 Time Error for July 12, 1997 70

Figure 5.20 Mean UCE Sum for July 12, 1997 70 


\section{List of Tables}

Table 3.1 Simulation Parameters for Simple Isolated Power Systems ...................... 32

Table 3.2 Interpretation of Parameters Used in the General Model for Turbines ....... 46

Table A.1 Newfoundland and Labrador Hydro Generating Units .............................. 83 


\section{Nomenclature}

\section{ACE : Area Control Error}

AGC : Automatic Generation Control

B : System bias factor (MW/0.1 Hz)

$\beta \quad$ : $\quad$ System response characteristic

CAP : Unit MW generating capacity

D : Load damping constant

DTS : Dispatcher Training Simulator

$\Delta f \quad: \quad$ Incremental frequency deviation

$\Delta \omega \quad$ : Incremental speed (angular frequency) deviation

$\Delta P_{G} \quad: \quad$ Incremental generation change

$\Delta \mathrm{P}_{\mathrm{L}} \quad$ : Incremental load demand change

$\Delta \mathrm{P}_{\mathrm{m}} \quad$ : Incremental mechanical power change

$\Delta \mathrm{P}_{\text {tie }} \quad: \quad$ Incremental tie-line power deviation

EDC : $\quad$ Economic Dispatch Control

EMS : $\quad$ Energy Management System

$\mathrm{f}_{\text {des }} \quad$ : $\quad$ Desired system frequency

$\mathrm{f}_{\text {sys }} \quad$ : Nominal system frequency

$\mathrm{H}$ : Inertia constant

LRA : Load reference actuator or load reference setpoint

M : Inertia Constant (2H) 


\begin{tabular}{|c|c|c|}
\hline $\mathrm{MW}$ & : & Megawat \\
\hline NERC & & North American Electric Reliability Council \\
\hline NLH & : & Newfoundland and Labrador Hydro \\
\hline$P_{\text {tie }}$ & : & Tie-line power \\
\hline $\mathrm{Pu}$ & : & per unit \\
\hline $\mathrm{R}$ & : & Speed regulation or droop \\
\hline $\mathrm{SACE}$ & : & Smoothed ACE \\
\hline SRC & : & System response characteristic \\
\hline $\mathrm{T}_{\mathrm{G}}$ & : & Speed governor time constant \\
\hline $\mathrm{T}_{\mathrm{RH}}$ & : & Reheat time constant (steam turbines) \\
\hline $\mathrm{T}_{\mathrm{T}}$ & : & Turbine time constant \\
\hline $\mathrm{T}_{w}$ & : & Water starting time constant (hydraulic turbines) \\
\hline
\end{tabular}




\section{Chapter 1}

\section{Introduction}

The existing operating conditions for the Newfoundland and Labrador Hydro (NLH) Power System are unique for North America. The NLH power system operates isolated from the North American Interconnected Power Grid. This isolation means that there is no tie-line power interchange with other utilities or control areas. In addition, the on-line generation and the peak loads vary greatly from season to season. During the winter months when the peak load is greatest, the matching generation is a mixture of automatically controlled hydroelectric generating units and manually controlled thermal generating units. In contrast, during the summer months, the peak load is reduced significantly and the manually controlled thermal generating units are taken off-line for maintenance. The change in load level is primarily due to a drop in residential electric heating requirements (there is no air-conditioning load as compared to the remainder of the continent).

In an interconnected electrical power system, as the load varies, the frequency and tie-line power interchange also vary. To accomplish the objective of regulating system electrical frequency error and tie-line flow deviation to zero, a supplementary control action to control the load reference setpoints of selected generating units is utilized. This control process is referred to as Automatic Generation Control (AGC). The control signal used is the Area Control Error (ACE) and is made up of the tie-line flow deviation added 
to the frequency deviation weighted by a bias factor. For the isolated system, the tie-line power interchange is zero so that the ACE depends only on the frequency error and bias factor.

Common practice in North American AGC systems is to use a constant bias factor nearly equal to the system response characteristic (SRC). Since the ACE relies on both the frequency error and bias factor for an isolated power system, proper selection of the bias factor is important for frequency regulation. The current practice at NLH is to use a constant bias factor for calculating the ACE.

In recent years, researchers have investigated the use of a bias factor that is dynamically calculated providing a closer approximation to the SRC. Since the SRC cannot be continuously measured, it is estimated using the bias factor. If the bias factor can be varied to match the SRC closely, the number of control actions will be reduced, thereby providing better control while still maintaining the frequency error at zero. Past research in the area of AGC performance using the SRC approximation concept is discussed in Section 2.4 .

\subsection{Aim of Thesis}

The aim of the thesis is as follows:

- To illustrate the concepts of power system models in order to investigate the dynamics of power system operation.

- To investigate the traditional methods of Automatic Generation Control using the computer simulation of simple power system models. Models of simple isolated 
power systems, subjected to step load changes, will illustrate the basic concepts of AGC required in this research, and provide the basis for using a variable bias factor.

- To implement, test and simulate an actual isolated power system. This will justify the use of the simulation model to investigate system dynamics.

- To design and investigate, using computer simulation of an actual isolated power system, the utilization of various dynamic bias factor calculation methods. This will aid in the determination of an optimal control method to improve frequency regulation. The optimal method will be determined using a set of performance indices such as the accumulated time error and the unit control error. Extensive simulations are carried out using data representing several different operating conditions.

The computer simulation models were developed using a software tool that provided both dynamic control system modeling and graphical output capabilities. The software package MATLAB ${ }^{\oplus}$ by The Mathworks, Inc. provided the modeling, analysis and graphical output functions necessary to simulate the dynamics of the automatic generation control process and the overall power system response to the AGC process. Further details on the simulation tools are given in Section 3.2.

\subsection{Thesis Organization}

The thesis is organized into six chapters. Chapter two reviews the concepts of Automatic Generation Control describing the basics of modeling power system components, the concepts of active power and frequency control, the fundamentals of 
AGC, and a discussion on performance and costs aspects. Chapter three presents the concept of computer simulation of simple power system configurations to investigate active power and frequency control by describing the simulation tools, the models, and the assumptions made to simplify the complexity of the power system. The fourth chapter presents the general procedure followed in simulating the NLH power system, and the formulation of the different dynamic bias factor calculation methods. In chapter five, the simulation results are presented and analyzed to determine the optimal control method. Finally, chapter six concludes the thesis with the contributions made by this research as well as some recommendations for the implementation of these findings in the NLH Energy Management System. 


\section{Chapter 2}

\section{Automatic Generation Control in Power Systems}

\subsection{Introduction}

One of the most important components in the daily operation of an electrical power system is the scheduling and control of generation. This function is the primary concern of the Energy Control Centre, and is largely provided by an Automatic Generation Control (AGC) program implemented as part of the Energy Management System (EMS). Although the process is highly automated, power system dispatchers can interact with it by monitoring its results and inputting data that reflect the current operating conditions.

In general, electrical power systems are interconnected to provide secure and economical operation. The interconnection is typically divided into control areas, with each consisting of one or more power utility companies [1]. The control areas are connected by transmission lines commonly referred to as tie-lines and the power flowing between control areas is called tie-line interchange power. One of the main responsibilities of each control area is to supply sufficient generation to meet the load demand of its customers, either with its own generation sources or with power purchased from other control areas. 
An essential part of an interconnected system is that all generators in the system respond to changes in frequency via their governor speed control. When the load increases in a particular control area, it is supplied initially by the kinetic energy stored in the rotating masses of the turbine generators. The result is a drop in the system frequency throughout the interconnected system. All generators in the interconnection respond to the speed change and adjust generation to return the frequency to a new steady-state value, thereby establishing a balance between the total system generation and the total system load. It is the function of AGC in the disturbed control area to readjust its generation in an economical manner such that any tie-line interchange power deviation that resulted from the load change is returned to zero, and the new steady-state frequency is brought back to the scheduled value.

For an isolated power system, the tie-line interchange power is zero, and hence it is the sole responsibility of the isolated control area to meet its own load demand and maintain the system frequency at its scheduled value. For a large system, in which the total inertia of the on-line generators is large, regulating the frequency is a challenging task even for the $\mathrm{AGC}$ function. As a result, the accumulated time error is typically much greater in an isolated system since the frequency error tends to be sustained for longer periods of time while the $\mathrm{AGC}$ process operates.

Understanding the characteristics of power system equipment is key in the study of AGC. Figure 2.1 depicts the basic control structure of an electrical power system. The primary components to consider are the synchronous generators; the prime movers (hydraulic and steam turbines); the speed-governing system, which includes the governor 
and the load reference actuator (speed changer); the unit controller and the AGC system. Section 2.2 presents the mathematical models developed for these components.

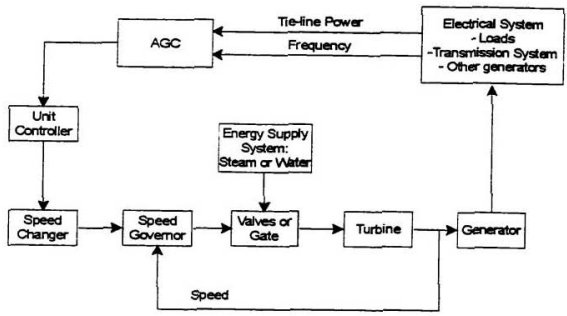

Figure 2.1 Basic power system control structure

The speed-governing system provides a primary control function that responds quickly to frequency changes caused by a change in the active power balance between generation and load. For governors with speed-droop characteristics, a steady-state frequency deviation from the desired system frequency remains following the primary control action. This deviation is corrected using the AGC function. Compared to the primary control process, this control is slower to respond to changes in the load demand. The fundamentals of AGC are described in detail in Section 2.3.

Automatic generation control has been utilized by power utilities for several decades. The approach used today generally provides acceptable levels of performance based primarily upon AGC operation criteria specified by the North American Electric Reliability Council (NERC) [2]. Of course, problems with AGC do exist since operating 
conditions are continually changing. These problems are related to the performance of AGC (such as the accumulation of time error and the inadvertent interchange of power) and the cost associated with it (such as maintenance of generating units and the availability of the energy source). These aspects of AGC and others have been researched, and are discussed briefly in Section 2.4 .

\subsection{Power System Equipment Characteristics and Modeling}

\subsubsection{The Synchronous Generator}

In an electrical power system, the principal source of electric energy is the synchronous generator. Related to the mechanical rotation of the synchronous generator's rotor is the electrical frequency. This electrical frequency depends on achieving a balance in the active power (electrical and mechanical torques), or a match between the electrical power output of the generator and the system load. When a load change does occur, there is an instantaneous change in the electrical torque of the generator, and hence an unbalance between the mechanical and electrical torques. This is reflected as a net accelerating (decelerating) torque given as

$$
T_{s}=T_{m}-T_{e}
$$

where $T_{a}=$ accelerating torque $[\mathrm{N} \cdot \mathrm{m}]$,

$\mathrm{T}_{\mathrm{m}}=$ mechanical torque $[\mathrm{N} \cdot \mathrm{m}]$, and

$\mathrm{T}_{e}=$ electrical torque $[\mathrm{N} \cdot \mathrm{m}]$. 
For a generator, the mechanical and electrical torques are both positive.

The combined inertia of the generator and the prime mover is accelerated by the unbalance in the applied torques. This gives us the equation of motion described as

$$
J \frac{d \omega_{m}}{d t}=T_{a}=T_{m}-T_{e}
$$

where $\mathrm{J}=$ combined moment of inertia of generator and turbine $\left[\mathrm{kg} \cdot \mathrm{m}^{2}\right]$,

$$
\begin{aligned}
& \left.\omega_{m}=\text { angular velocity of the rotor [mech. } \mathrm{rad} / \mathrm{s}\right] \text {, and } \\
& \mathrm{t}=\text { time }[\mathrm{s}] .
\end{aligned}
$$

Defining the inertia constant $\mathrm{H}$ as the kinetic energy in watt-seconds at rated speed divided by the VA base, or

$$
\mathrm{H}=\frac{1}{2} \frac{\mathrm{J} \omega_{0 \mathrm{~m}}^{2}}{\mathrm{VA}_{\text {base }}}
$$

$\mathrm{J}$ may be written in terms of $\mathrm{H}$ as

$$
J=\frac{2 H}{\omega_{0 \mathrm{~m}}^{2}} V A_{\text {base }}
$$

Substituting Eq. (2.4) into Eq. (2.2) gives

$$
\frac{2 \mathrm{H}}{\omega_{0 \mathrm{~m}}^{2}} \mathrm{VA} A_{\text {base }} \frac{\mathrm{d} \omega_{\mathrm{m}}}{\mathrm{dt}}=\mathrm{T}_{\mathrm{m}}-\mathrm{T}_{\mathrm{e}}
$$

Using $\mathrm{T}_{\text {base }}=\mathrm{VA}_{\text {base }} / \omega_{0 \mathrm{~m}}$, the per unit form of Eq. (2.5) is

$$
2 \mathrm{H} \frac{\mathrm{d} \bar{\omega}_{\mathrm{r}}}{\mathrm{dt}}=\overline{\mathrm{T}}_{\mathrm{m}}-\overline{\mathrm{T}}_{\mathrm{c}}
$$

where $\bar{\omega}_{\mathrm{r}}=\omega_{\mathrm{m}} / \omega_{0 \mathrm{~m}}=\omega_{\mathrm{r}} / \omega_{0}$,

$$
\begin{aligned}
& \left.\omega_{\mathrm{r}}=\text { angular velocity of rotor [elec. } \mathrm{rad} / \mathrm{s}\right], \text { and } \\
& \omega_{0}=\text { rated angular velocity [elec. rad/s]. }
\end{aligned}
$$


Here the superbar notation denotes a per unit quantity. Next, setting the mechanical starting time $\mathrm{M}$ to be

$$
\mathrm{M}=2 \mathrm{H} \quad[\mathrm{s}]
$$

the equation of motion may be written as

$$
\mathrm{M} \frac{\mathrm{d} \bar{\omega}_{\mathrm{r}}}{\mathrm{dt}}=\overline{\mathrm{T}}_{\mathrm{m}}-\overline{\mathrm{T}}_{\mathrm{c}}
$$

Note that the term inertia constant will be used for both $\mathrm{M}$ and $\mathrm{H}$ interchangeably.

For the study of $\mathrm{AGC}$, it is preferable to express the relationship given in Eq. (2.8) in terms of mechanical and electrical power rather than torque. The relationship between power $\mathrm{P}$ and torque $\mathrm{T}$ is given by

$$
\mathrm{P}=\omega_{\mathrm{r}} \mathrm{T}
$$

Since we are considering small deviations (denoted by the prefix $\Delta$ ) from initial values (denoted by subscript ${ }_{0}$ ), we may write

$$
\begin{aligned}
& \mathrm{P}=\mathrm{P}_{0}+\Delta \mathrm{P} \\
& \mathrm{T}=\mathrm{T}_{0}+\Delta \mathrm{T} \\
& \omega_{\mathrm{r}}=\omega_{0}+\Delta \omega_{\mathrm{r}}
\end{aligned}
$$

Substituting Eq. (2.10) into Eq. (2.9) gives

$$
\mathrm{P}_{0}+\Delta \mathrm{P}=\left(\omega_{0}+\Delta \omega_{\tau}\right)\left(\mathrm{T}_{0}+\Delta \mathrm{T}\right)
$$

Neglecting higher order terms and considering only the relationship between perturbed values yields

$$
\Delta \mathrm{P}=\omega_{0} \Delta \mathrm{T}+\mathrm{T}_{0} \Delta \omega_{r}
$$

Therefore

$$
\Delta \mathrm{P}_{\mathrm{m}}-\Delta \mathrm{P}_{\mathrm{e}}=\omega_{0}\left(\Delta \mathrm{T}_{\mathrm{m}}-\Delta \mathrm{T}_{\mathrm{e}}\right)+\left(\mathrm{T}_{\mathrm{m} 0}-\mathrm{T}_{\mathrm{eo}}\right) \Delta \omega_{\mathrm{r}}
$$


Now, in steady state, electrical and mechanical torques are equal, $T_{m 0}=T_{e 0}$, and with speed expressed in per unit, $\omega_{0}=1$, we have

$$
\Delta \mathrm{P}_{\mathrm{m}}-\Delta \mathrm{P}_{\mathrm{e}}=\Delta \mathrm{T}_{\mathrm{m}}-\Delta \mathrm{T}_{\mathrm{e}}
$$

Hence, the equation of motion may now be rewritten as

$$
M \frac{d \omega_{t}}{d t}=P_{m}-P_{e}
$$

where $\mathrm{M}$ is in units of seconds and all other quantities are in per unit.

For analysis of power system dynamic performance, Eq. (2.15) is expressed in the Laplace domain such that the transfer function is

$$
\operatorname{Ms} \Delta \omega_{\mathrm{r}}=\Delta \mathrm{P}_{\mathrm{m}}-\Delta \mathrm{P}_{\mathrm{e}}
$$

Solving for the frequency change,

$$
\Delta \omega_{\mathrm{r}}=\frac{1}{\mathrm{Ms}}\left(\Delta \mathrm{P}_{\mathrm{m}}-\Delta \mathrm{P}_{\mathrm{e}}\right)
$$

Next, to account for the resistive (frequency independent) and motor (frequency dependent) loads, the change in electrical power is expressed as

$$
\Delta \mathrm{P}_{\mathrm{e}}=\Delta \mathrm{P}_{\mathrm{L}}+\mathrm{D} \Delta \omega_{\mathrm{c}}
$$

where $\Delta \mathrm{P}_{\mathrm{L}}=$ non-frequency sensitive load change,

$$
\begin{aligned}
& D \Delta \omega_{\mathrm{r}}=\text { frequency sensitive load change, and } \\
& \mathrm{D}=\text { load damping constant. }
\end{aligned}
$$

Here the damping constant is expressed as a percent in load for one percent change in frequency. Substituting Eq. (2.18) into Eq. (2.17) and solving for the frequency change gives 


$$
\Delta \omega_{r}=\frac{1}{M s+D}\left(\Delta P_{m}-\Delta P_{L}\right)
$$

This equation describes the dynamics of the synchronous generator by giving the frequency deviation that results from a mismatch between the MW generation and the load demand. It also takes into account the total inertia of the power system, as well as the frequency dependent and independent components of the load. For a power system with more than one generating unit, we may write

$$
\Delta \omega_{\mathrm{r}}=\frac{1}{\mathrm{M}_{\mathrm{eq}} \mathrm{s}+\mathrm{D}}\left(\Delta \mathrm{P}_{\mathrm{ri}}-\Delta \mathrm{P}_{\mathrm{L}}\right)
$$

where $\Delta \mathrm{P}_{\mathrm{mi}}=$ mechanical power change for generating unit $\mathrm{i}[\mathrm{pu}]$,

$$
\begin{aligned}
& \mathrm{M}_{\mathrm{eq}}=\sum \mathrm{M}_{\mathrm{i}}[\mathrm{s}] \text {, and } \\
& \mathrm{M}_{\mathrm{i}}=\text { inertia constant of generating unit } \mathrm{i}[\mathrm{s}] .
\end{aligned}
$$

This assumes that all generators respond coherently to changes in system load, enabling them to be represented by an equivalent generator.

\subsubsection{Speed Governing Fundamentals}

For two or more generating units connected in parallel in a power system to meet the load demand, speed governors with speed droop characteristics (rotor speed drops as the load is increased) are commonly utilized. The speed droop, or regulation, governor uses the principle of steady-state feedback resulting in a steady-state frequency deviation. This means a unique operating frequency exists at which all on-line generating units can meet the load demand. 
The operation of the governor is based on the creation of a control signal $\Delta Y$ that actuates the main steam supply valves for the steam turbine or the gates for the hydraulic turbine. For the speed droop governor, the speed deviation $\Delta \omega_{\mathrm{r}}$ (measured rotor speed $\omega_{\mathrm{r}}$ minus the reference speed $\omega_{0}$ ) is compared with a steady-state feedback portion of $\Delta Y$. The resulting error signal $\mathrm{E}$ is then amplified and integrated to give the control signal $\Delta Y$. This process is illustrated in Figure 2.2.

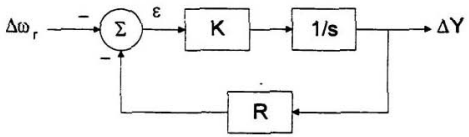

Figure 2.2 Speed governor with steady-state feedback

The transfer function of the governor is obtained by reducing the feedback of $\Delta \omega_{r}$ to obtain $\Delta Y$. First writing $\Delta Y$ as a function of the error signal gives

$$
\Delta Y=\frac{K}{s} \varepsilon
$$

where $\varepsilon=-\Delta \omega_{\mathrm{r}}-\mathrm{R} \Delta \mathrm{Y}$. Substituting the expression for $\varepsilon$ into Eq. (2.21) gives

$$
\Delta Y=\frac{K}{s}\left[-\Delta \omega_{r}-R \Delta Y\right]=-\frac{K}{s} \Delta \omega_{r}-\frac{K R}{s} \Delta Y
$$

Now solving for $\Delta Y$ in terms of $\Delta \omega$, and setting $T_{C}=1 / K R \equiv$ Govemor Time Constant, yieids

$$
\Delta \mathrm{Y}=-\frac{1}{\mathrm{R}} \frac{1}{1+\mathrm{s} \mathrm{I}_{\mathrm{G}}} \Delta \omega_{\mathrm{r}}
$$

This transfer function describes a proportional controller with a gain of $1 / R$. 
The value of $R$ determines the steady-state speed versus load characteristic of a generating unit as depicted in Figure 2.3 on the following page. This figure depicts the ideal linear characteristic. In actual practice, the characteristic is non-linear depending primarily on the movement of valves and gates. The parameter $R$ is commonly referred to as the speed regulation or droop, and is expressed as

$$
\mathrm{R}=-\frac{\Delta \omega_{\mathrm{r}}}{\Delta \mathrm{Y}}=-\frac{\Delta f}{\Delta \mathrm{P}}
$$

where $\Delta f=$ frequency deviation, and

$$
\Delta \mathrm{P}=\text { power output deviation }
$$

or in percent as

$$
\begin{aligned}
\text { Percent } R & =\frac{\text { percent speed or frequency change }}{\text { percent power output change }} \times 100 \\
& =\left(\frac{\omega_{\mathrm{NL}}-\omega_{\mathrm{FL}}}{\omega_{0}}\right) \times 100
\end{aligned}
$$

where $\omega_{\mathrm{NL}}=$ steady-state speed at no load,

$\omega_{\mathrm{FL}}=$ steady-state speed at full load, and

$\omega_{0}=$ nominal or rated speed.

For example, a $5 \%$ droop of regulation means a $5 \%$ frequency deviation causes a $100 \%$ change in valve position or power output. 


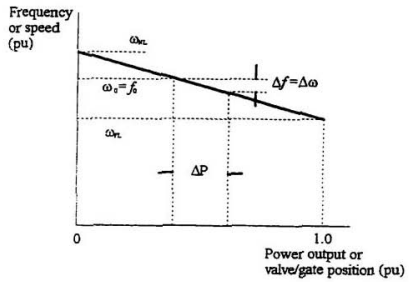

Figure 2.3 Ideal steady-state characteristics of a governor with speed droop

If two or more generators with speed droop governor characteristics are connected in parallel, there exists a unique frequency at which they share the load change. At this new common operating frequency $f^{\prime}$, the amount of load that each unit picks up depends on the droop characteristic. So at $f^{\prime}=f_{0}+\Delta f$, there is a corresponding change in generation. This means that if the load increases by $\Delta P_{L}$, there is a corresponding decrease in the speed of the generating unit causing the governors to increase the power output.

The steady-state error resulting from a change in load can be adjusted by changing the load reference setpoint of the speed governor. This is accomplished by operating the load reference actuator, or speed changer motor. In its simplest form, the load reference actuator is essentially an amplifier and an integrator that acts on the control signal determined by the unit controller. The effect of the speed changer is to shift the droop characteristic up and down, thereby varying the power output of the unit for a given 
system frequency as shown in Figure 2.4. The three characteristics depicted in this figure are for a speed governor associated with a $60 \mathrm{~Hz}$ system, and represent three different load reference settings. At $60 \mathrm{~Hz}$, the load reference setting represented by characteristic A results in a zero output, characteristic B results in 50\% output, and C results in $100 \%$ power output. So at any given speed, the power output of the generating unit may be adjusted to any desired value via the load reference actuator.

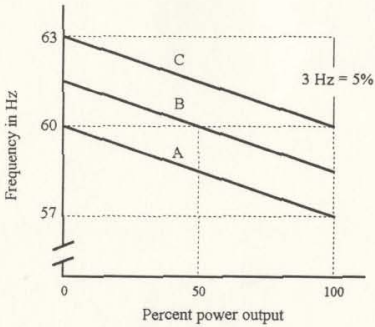

Figure 2.4 Effect of speed-changer setting on governor characteristic

The effects of the droop of all generator speed governors and all of the system loads can be combined in a similar manner as the inertia constants (see Eq. (2.20)). This represents the composite power/frequency characteristic of the power system. For a system with $n$ generators and a composite load damping constant $\mathrm{D}$, the steady-state frequency deviation following a load change of $\Delta \mathrm{P}_{\mathrm{L}}$ is given by

$$
\Delta f_{S S}=\frac{-\Delta \mathrm{P}_{\mathrm{L}}}{\left(1 / \mathrm{R}_{1}+1 / \mathrm{R}_{2}+\cdots+1 / \mathrm{R}_{n}\right)+\mathrm{D}}=\frac{-\Delta \mathrm{P}_{\mathrm{L}}}{1 / \mathrm{R}_{e q}+\mathrm{D}}
$$


where

$$
\mathrm{R}_{e q}=\frac{1}{1 / \mathrm{R}_{1}+1 / \mathrm{R}_{2}+\cdots+1 / \mathrm{R}_{n}}
$$

Thus, the composite frequency, or system, response characteristic in per unit is

$$
\beta=\mathrm{SRC}=\frac{-\Delta \mathrm{P}_{\mathrm{L}}}{\Delta f_{s s}}=\frac{1}{\mathrm{R}_{\text {eq }}}+\mathrm{D}
$$

This characteristic is highly variable and non-linear, and describes the system response to changes in frequency. It is usually estimated with a straight-line approximation that has units of $\mathrm{MW} / 0.1 \mathrm{~Hz}$.

\subsubsection{Prime Movers and their Speed-Governing Systems}

Two main sources of electrical energy supplied by utilities are the kinetic energy of water and the thermal energy derived from fossil fuels. The prime movers convert these sources of energy into mechanical energy that is subsequently converted to electrical energy by synchronous generators. The two main types of prime movers are the hydraulic turbine and steam turbine. The speed governing systems of these turbines are based on the speed-droop characteristic presented in Section 2.2.2. The only difference is the hydraulic turbine requires transient droop compensation for stable speed control performance.

The hydraulic turbine transient characteristics are determined from the water feeding the turbine via the penstock. The main parameter used in describing the turbine's 
dynamics is the water starting time $T_{w}$. This tepresents the time required for the head $\mathrm{H}_{0}$ to accelerate the water in the penstock from standstill to the velocity $\mathrm{U}_{0}$, or

$$
T_{w}=\frac{L U_{0}}{a_{B} H_{0}}
$$

where $\mathrm{a}_{\mathrm{g}}=$ acceleration due to gravity, and

$\mathrm{L}=$ length of the penstock.

The value of $\mathrm{T}_{w}$ is load dependent, but is assumed constant for small-signal analysis.

Using the water starting time, a transfer function describing how the turbine power output changes in response to a change in the gate position $\Delta G$ is given as

$$
\Delta P_{\mathrm{m}}=\frac{1-s \mathrm{~T}_{w}}{1+s \frac{1}{2} \mathrm{~T}_{w}} \Delta G
$$

This model represents the ideal lossless hydraulic turbine.

As mentioned previously, hydroturbines require transient droop compensation for control of the gate position. Since a gate position change initially produces a turbine power change opposite to what is desired, the speed governor was designed with a large transient droop and a long reserting time. As a result, the response of a hydro generating unit to a change in speed or to a change in the load reference setpoint is relatively slow. A linear approximation of the speed governor with transient droop is given as

$$
\Delta G=-\frac{1}{R_{P}} \cdot \frac{1+s T_{R}}{1+s\left(R_{T} / R_{P}\right) T_{R}} \cdot \frac{1}{1+s T_{G}} \Delta \omega_{r}
$$

where $R_{p}=$ permanent speed droop,

$$
\begin{aligned}
& R_{T}=\text { temporary or transient speed droop, and } \\
& T_{R}=\text { reset time. }
\end{aligned}
$$


This equation has the same form as Eq. (2.23) but with the transient droop compensation component included.

A steam turbine converts stored energy of high pressure and bigh temperature steam into rotating energy, which is then converted into electrical energy by the generator. The steam boiler heat source can be a fossil-fuelled furnace or a nuclear reactor. The steam turbine control is accomplished via governor-controlled valves.

Steam turbines normally consist of two or more turbine sections coupled in series. Fossil-fuelled generating units have bigh pressure (HP), intermediate pressure (IP) and low pressure (LP) turbine sections, and are classified as reheat type or non-reheat type. In the reheat type turbine, the steam, upon leaving the HP section, returns to the boiler to be reheated, and then is passed onto the IP section. In contrast, the non-reheat type turbine passes the steam directly from the HP section to the IP section. The reheat process improves the efficiency of the steam turbine but at a slightly higher cost.

The simplified transfer function describing how the turbine power output changes in response to a change in the control valve position $\Delta V_{C V}$ is given as

$$
\Delta \mathrm{P}_{\mathrm{m}}=\frac{1+s \mathrm{~F}_{\mathrm{HP}} \mathrm{T}_{\mathrm{RH}}}{\left(1+s \mathrm{~T}_{\mathrm{CH}}\right)\left(1+s \mathrm{~T}_{\mathrm{RH}}\right)} \Delta \mathrm{V}_{\mathrm{CV}}
$$

where $T_{C H}=$ main inlet volumes and steam chest time constant,

$$
\begin{aligned}
& T_{R H}=\text { reheat time constant, and } \\
& F_{H P}=\text { fraction of total turbine power generated by the HP section. }
\end{aligned}
$$

This equation describes the reheat type turbine. For the non-reheat type, $T_{R H}=0$, and the power output is 


$$
\Delta \mathrm{P}_{\mathrm{m}}=\frac{1}{1+\mathrm{sT}_{\mathrm{CH}}} \Delta \mathrm{V}_{C V}
$$

The speed governor function for the steam turbine is to adjust the position of the control valves to control the admission of steam to the turbine. It is very similar to the hydroturbine governing system except that the reset time $T_{R}$ is zero, which gives the valve position expressed as

$$
\Delta \mathrm{V}_{C V}=-\frac{1}{\mathrm{R}} \frac{1}{1+\mathrm{sT} \mathrm{T}_{\mathrm{G}}} \Delta \omega_{r}
$$

This is essentially the basic speed governor relationship given in Eq.(2.23).

\subsubsection{The Unit Controller}

The unit controller provides the control signal to activate the load reference actuator. This control signal, known as the unit control error (UCE), is the difference between the unit MW output and the desired generation (economic basepoint plus the AGC control signal). Its main function is to regulate the UCE to zero by issuing raise/lower commands or a desired generation signal to the load reference actuator. This process changes the unit's actual MW output to match the desired MW generation. The unit controller inputs include its economic basepoint (which is the most economic desired unit MW generation as determined from the economic dispatch function), its actual MW output, and the portion of the AGC control signal assigned to the particular generating unit. If the unit is not AGC-controlled, the AGC control signal is zero. 
To avoid unnecessary swinging of the generating unit and to provide some degree of high frequency noise filtering, the UCE is typically accumulated until a threshold has been reached. If the accumulated UCE is greater than the threshold value, the difference between the two values is used to actuate the speed changer, and the accumulator is subsequently reset to zero. The process occurs at each AGC control interval.

\subsection{Automatic Generation Control Fundamentals}

The basic objectives of power system operation during normal operating conditions are associated with automatic generation control. These are:

(1) match total system generation to total system load;

(2) adjust system electrical frequency deviation to zero;

(3) maintain tie-line interchange powers at their scheduled values; and

(4) allocate generation in an economical manner.

The first objective is achieved with speed governor, or primary, control. The turbine speed governors, described in Section 2.2.2, respond proportionally to local frequency deviations, and normally bring the rate of change of frequency to zero in several seconds. The second and third objectives are met using load frequency, or secondary, control. This is a remote process that originates its control signal at the Energy Control Centre and can take tens of seconds to respond to normal load fluctuations. The last objective is part of economic dispatch, or tertiary, control (EDC). Based on the individual generating unit's cost curves, each EDC-controlled unit is assigned an economic basepoint and a set of participation factors. These factors determine the percentage of AGC control signal 
for each AGC-controlled generating unit. This signal then raises/lowers the economic basepoint (and hence, the governor droop characteristic via the speed changer), accordingly. The EDC calculations may take up to several minutes to take effect.

The control signal used to accomplish the AGC objectives is the area control error or $\mathrm{ACE}$. The $\mathrm{ACE}$ is given as

$$
\mathrm{ACE}=\Delta \mathrm{P}_{\text {tie }}+10 \mathrm{~B} \Delta f
$$

where $\Delta \mathrm{P}_{\text {tie }}=$ total control area tie-line interchange power deviation,

$\mathrm{B}=$ bias factor in $\mathrm{MW} / 0.1 \mathrm{~Hz}$, and

$\Delta f=$ frequency deviation.

In the Eq. (2.35), if B is too large or small, the result will be excess regulation under normal conditions. For example, if B is too small, the AGC process will tend to drive the frequency deviations larger and the tie-line deviations smaller than that resulting from the SRC. If B is too large, the frequency deviations will be smaller and tie-line deviations larger than that resulting from SRC. Thus, proper selection of the bias factor is vital to achieve good regulation of frequency.

For the isolated power system, the interchange power is zero, hence the function of $\mathrm{AGC}$ is to regulate the frequency error to zero, which gives the $\mathrm{ACE}$ as

$$
\mathrm{ACE}=10 \mathrm{~B} \Delta f
$$

Since the interchange power does not enter into the calculation, the proper selection of the bias factor is increasingly important.

The ACE is also filtered so that fast random variations in the load do not cause changes in the ACE. This minimizes unnecessary wear and tear on the speed governors, 
as well as the turbine valves and gates. The filtered or smoothed ACE (SACE) is then used to control generation without responding to these random components.

Poor regulation in an interconnected power system is reflected in the accumulation of time error and the flow of inadvertent power over tie-lines. In isolated systems, time error is a main concern (in addition to the economic operation of the power system). Time error, which can speed up or slow down clocks and result in a loss of billable load (these topics are discussed in Section 2.4), is minimized or corrected by offsetting the scheduled frequency from the desired value for a period of time. During this period, the frequency offset causes the accumulation of time error to decrease. This process is usually performed during light load periods.

Depicted in Figure 2.5 is the typical AGC process for an isolated power system [4]. It shows the ACE processor, the economic dispatch function, and the unit controller. The input to the ACE processor includes the time error correction, the bias factor, the scheduled frequency and the actual measured frequency. The economic dispatch function determines the economic basepoint for all generating units. The unit controller determines the unit control error and sends raise/lower pulses to the speed governor's load reference actuator. Typically, the execution cycle for the ACE processor is every $2-4$ seconds. 


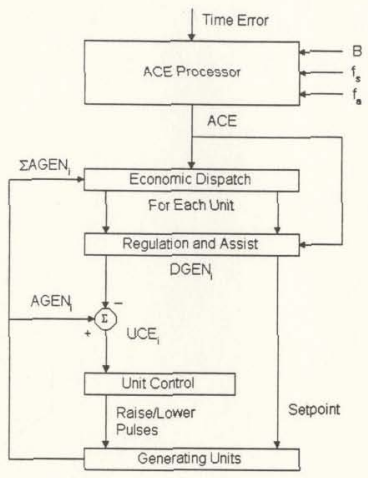

Figure 2.5 Typical AGC Process

\subsection{Automatic Generation Control Performance}

Automatic generation control is a relatively mature subject in the field of power systems energy management, evolving from early analog systems to the present digital systems. Today's AGC implementations are simple, yet robust, decentralized systems that control complex, highly non-linear, and continuously changing power systems. Part of the field of AGC is the determination of "how well" AGC implementations perform and at "what cost". The performance and economics of AGC have been a topic of discussion for many decades [5]-[8].

AGC performance parameters have been specified by the North American Electrical Reliability Council (NERC) for the North American Interconnected Power 
System. This regulatory body, based in the United States, provides a minimum set of AGC performance criteria for members of the interconnection. These performance measures are based upon the ACE. For normal operation, the criteria state that the ACE should equal zero at least once every 10 minutes. For disturbance conditions, the ACE must be returned to zero within 10 minutes following the disturbance.

Other criteria commonly used in interconnected power systems to provide a measure of AGC performance are integrated errors such as inadvertent line flow (the integral of tie-line interchange power deviations commonly referred to as inadvertent) and time error (the integral of frequency error). For the isolated power system, the interchange of power is zero hence the inadvertent is zero. Time error (and inadvertent for interconnected systems) is a result of a deviation between the actual system frequency and the desired value, arising from a mismatch in generation and load demand. The control of generating units is required via primary and secondary control to maintain a frequency of $60 \mathrm{~Hz}$ and match generation to load. If time error accumulation can be reduced with little or no increase in unit control, an improvement in AGC performance of the isolated system may be achieved. If increased unit control is necessary to meet the AGC objectives, the additional generator movement results in increased wear and tear of the units and additional operation costs in the form of increased fuel consumption and maintenance. Thus, the unit control error (or its integral, the load reference setpoint) should be used in conjunction with the time error when evaluating AGC performance. No gain is achieved if time error reduces at an increase in cost and a decrease in the life of generating units due to increased unit control. 
AGC imposes an economic burden on the day-to-day operations of a power utility. From the initial implementation and ongoing maintenance costs to such things as the uneconomic loading of generating units, lost sales due to time error, wear and tear due to increased generator movement, and even spillage of the precious water supply, the cost of operating a power system involves many factors. A well-tuned AGC process will provide the necessary regulation required to minimize time error accumulation and inadvertent power interchange while at the same time working in conjunction with the dispatch function to load generating units in the most economical manner.

Many researchers have suggested methods to improve the AGC algorithm, and hence the frequency regulation, by using dynamically calculated bias factors [7], [9]-[11]. The dynamic bias factor attempts to follow the power system natural response to frequency changes more closely. This process reduces the number of unnecessary control actions thereby providing better control of frequency. Oni, Graham and Walker [9] describe a method that experimentally determines the SRC from the generation-frequency response characteristic and the load-frequency characteristic without AGC action present. These characteristics were graphically combined to obtain the SRC that was then used as the non-linear bias factor in AGC calculations. A similar method proposed by Kennedy, Hoyt and Abell [10] suggests using a variable and non-linear bias factor that is modeled to match the SRC by monitoring the system load and on-line generation. Each of these approaches has yielded favorable results for interconnected power systems in which tieline power interchange is a factor. 


\subsection{Summary}

This chapter has discussed the basic control scheme of an electrical power system with respect to active power and frequency. Since the flows of active power and reactive power in a transmission system (which are closely related to frequency and voltage, respectively) are essentially independent of each other and are influenced by different control actions, the control of frequency and voltage can also be considered separate. This independence enables the study of automatic generation control without the consideration of the individual bus voltages.

Mathematical models and qualitative descriptions of various components of the power system have been presented. This background information will be used to develop a dynamic control model of an electrical power system to be implemented in a computer simulation program. Simple single and multi-machine isolated power systems will be constructed to investigate the effect of a varying bias factor on the AGC process. In addition, an actual isolated power system modeled on the Newfoundland and Labrador Hydro system will be similarly implemented and simulated to investigate a dynamically calculated bias factor based on some system characteristic such as the load level, or the type or number of generating units supplying the load demand.

Poor regulation and/or inadequate dispatch of generation in an isolated power system cause time error and ensuing correction procedures. This can translate into further regulation, loss of billable load, and lost dollars or savings pending on the cost of generation at the time that time error is incurred versus the costs during the correction periods. AGC performance measurement is necessary to judge primarily how well AGC 
aids in the regulation of frequency, and secondly, at what cost it accomplishes its objectives. Cost of frequency regulation will not be discussed further in this report although it is an important part when considering AGC performance. The focus will be on improvements made to the overall system regulation when changes are made to the basic AGC process, that is, the use of a dynamic bias factor. 


\section{Chapter 3}

\section{AGC Simulation Models}

\subsection{Introduction}

To investigate the dynamics of a power system, and hence, the AGC process, two methods are available. First, on-line investigation is possible by implementing the proposed bias factor calculation method in the EMS software. The feasibility of this method is questionable since varying the bias factor may cause system instability, or unwanted generation movement resulting in uneconomical operation and excessive control of generators.

A second method involves modeling the power system using a computer simulation software program. This method is preferred since accurate models have been developed that allow the power system researcher to investigate the dynamic performance of the electrical power system. Combining the individual models into a single entity provides a simple small-signal model of the power system dynamics. As shown in Chapter 2, these models are readily available and can be implemented using a control system simulation software program. Following sufficient simulation testing, on-line implementation and testing may be carried out to further verify the simulation findings.

This first section of this chapter describes the simulation software tools utilized in the investigation of the AGC process for an isolated power system. For simulation and 
analysis purposes, a software package, MATLAB [12], distributed by The MathWorks, Inc. provides the required dynamic modeling and graphical output capabilities. The second section presents the simulation of some simple power systems that provide the basis for the dynamic bias factor investigation. This includes the simulation results for simple single and multi-machine isolated power systems. The third section identifies the assumptions that were made to simplify the NLH simulation model and the investigation procedure, and presents the simulation models for the NLH isolated power system.

\subsection{Simulation Tools}

For simulation and analysis, a software package that provided both dynamic control system modeling capabilities as well as the ability to display output in a graphical manner was necessary. The software package MATLAB ${ }^{\oplus}$ by The MathWorks, Inc., is a technical, user-friendly computing environment for high-performance numeric computation and visualization. All references to MATLAB in the thesis are with respect to the UNIX implementation of MATLAB using the X Window System.

SIMULINK $^{\circ}$ is an extension to MATLAB and provides an interface for simulating dynamic systems. SIMULINK adds many features specific to dynamic systems but retains all of MATLAB's general purpose functionality. Two phases are involved in the simulation process. First, a model is defined or an existing model is recalled. SIMULINK facilitates the model definition phase by utilizing block diagram windows that allow pre-defined model components to be manipulated. The pre-defined components include items such as the summation, the signal multiplexer, and the transfer 
function. The analysis phase is performed by either the selection of options from SIMULINK menus or by entering commands in the MATLAB command window. Graphical analysis is possible using both analysis methods. This allows the progress of the simulation to be viewed while it is running, and enables the results to be further manipulated in the MATLAB workspace upon simulation termination [13].

\subsection{Simple Isolated Power System}

To investigate the dynamics of the AGC process, simple isolated power systems were modeled and analyzed. The first two simulations consisted of power system models with a single hydro generating unit, with and without secondary control, respectively. These simulations were carried out to demonstrate the AGC process. A 1-MW step load change was used for the input. The third and fourth simulations demonstrate the effect of using a variable bias factor for the same single machine model. The bias factor changes to a new value (from the base value of $25 \mathrm{pu} \mathrm{MW} / 0.1 \mathrm{~Hz}$ ) following the load change.

The last simulation model consists of two AGC-controlled hydro generating units and a non-AGC controlled thermal generating unit. These simulations were carried out using different bias factors and were subjected to a 1-MW step load change. The system was configured so that the hydro units would adjust generation to meet the change in load demand while the thermal unit responded with primary control support but was later returned to its base loading. Parameters for all models were obtained from Kundur [3] and are representative of typical data used in AGC studies. The system data for the 
simulation models is provided in Table 3.1, while the power system models and simulation output data are depicted in the following figures.

Table 3.1 Simulation Parameters for Simple Isolated Power Systems

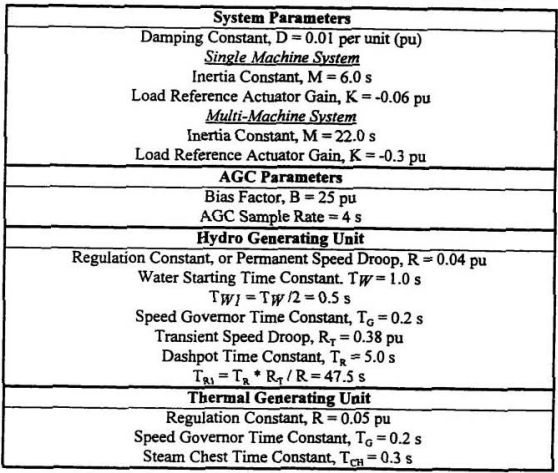

The simulation model for a single machine with only primary control is illustrated in Figure 3.1. The output data is given in Figure 3.2. When the system is subjected to a $+1-\mathrm{MW}$ step load change (dPL) as depicted in Figure 3.2(c), there is an initial drop in power output $(\mathrm{dPm})$ until the resulting frequency drop is sensed by the unit's speed governor (note that the load reference setpoint, LRA, is zero with only primary control present). At this time, the power output begins to increase in an attempt to match the load demand. After the primary control of the speed governor has time to react to the change 
in frequency, the frequency is returned to a steady-state value of $59.976 \mathrm{~Hz}$ and the power output has increased by 1-MW. Due to the frequency change from the scheduled value of $60 \mathrm{~Hz}$, there is a corresponding accumulation of time error as shown in Figure 3.2(b). This time error continues to increase while the frequency remains offset from $60 \mathrm{~Hz}$.

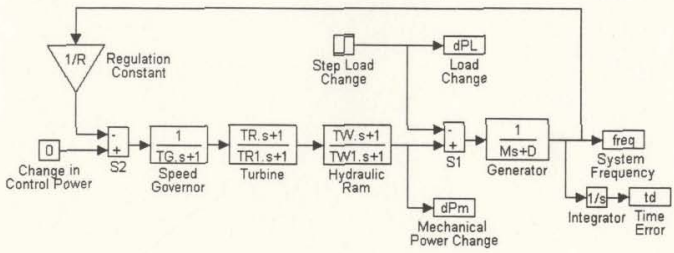

Figure 3.1 Single Hydro Generator with Primary Control Only

(a) System Frequency

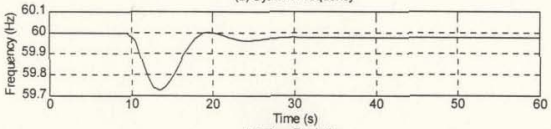

(b) Time Devation

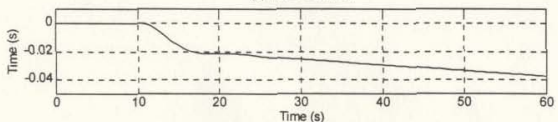

(c) Mecharical and Load Powers

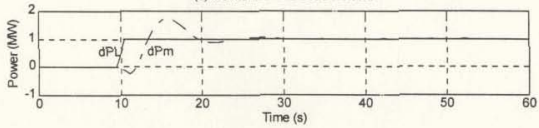

Figure 3.2 Output Data for Single Machine Model with Primary Control Only 
To halt the increase in time error, the frequency must be returned to the scheduled value. This is accomplished by adjusting the load reference setpoint of the unit's speed governor via secondary control. Figure 3.3 depicts the single machine with both primary and secondary control. As is evident in Figure 3.4(a), following the same +1-MW load change, the frequency is now returned to the scheduled value of $60 \mathrm{~Hz}$ and the load demand is met by a $+1-\mathrm{MW}$ increase in the unit's power output. In addition, the increase in time error has halted and has reached a steady-state value of -0.006 seconds. Note the relationship between the frequency and the ACE. Since there is no power interchange between this system and external control areas, the ACE is essentially a scaled version of the frequency response to the load change.

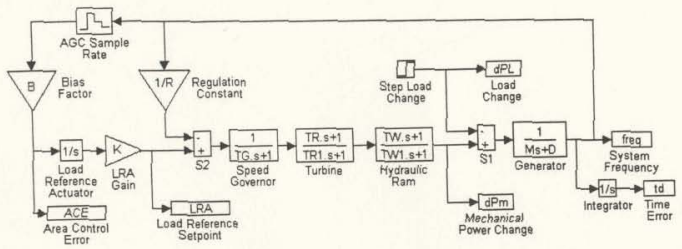

Figure 3.3 Single Hydro Generator with Primary and Secondary Control 
(a) System Frequency

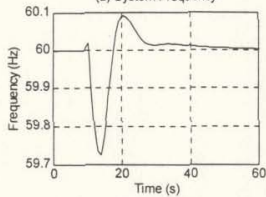

(c) Time Deviation

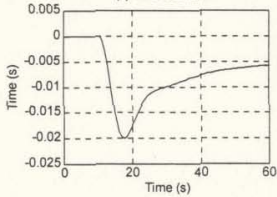

(b) Area Control Error (ACE)

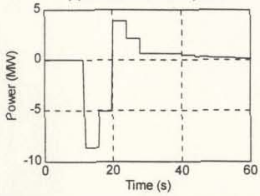

(d) Mecharical Power, Load Power \& Reference Setpoint

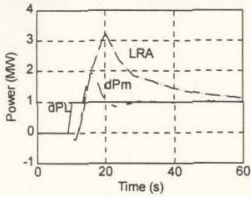

Figure 3.4 Simulation Data for Single Machine System with $B=25 \mathrm{pu} M W / 0.1 \mathrm{~Hz}$

The simulation results for the third and fourth simulations are shown in Figures 3.5 and 3.6, respectively. In Figure 3.5, the bias factor has been decreased from the base value of $25 \mathrm{pu} \mathrm{MW/0.1} \mathrm{Hz} \mathrm{to} 15 \mathrm{pu} \mathrm{MW/0.1} \mathrm{Hz}$. This change takes effect two seconds following the change in load (AGC measurements are typically performed on a two second cycle while AGC control commands are typically issued on a four second cycle. Use of a comparably larger or smaller quantity has minimal effect on the results). Here the $\mathrm{ACE}$ and the load reference setpoint (which both represent the amount of unit control) have been decreased in magnitude resulting in an increase in the steady-state time error ($0.0114 \mathrm{~s}$ from $-0.006 \mathrm{~s}$ ). In Figure 3.6, the bias factor is increased to $35 \mathrm{pu} \mathrm{MW/0.1} \mathrm{Hz}$. In this case, the ACE has increased but the steady-state time error has decreased to 0.0034 seconds. 
(a) System Frequency

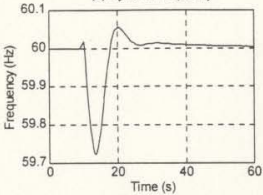

(c) Time Deviation

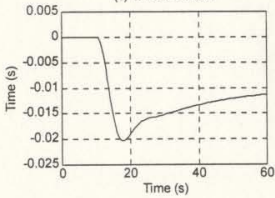

(b) Area Control Error (ACE)

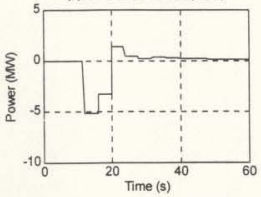

(d) Mecharical Power. Load Power \& Reference Setpoint

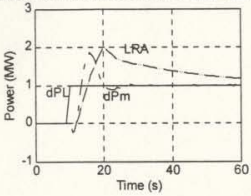

Figure 3.5 Decrease in Bias Factor for the Single Machine System

(a) System Frequency

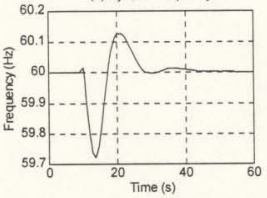

(c) Time Devation

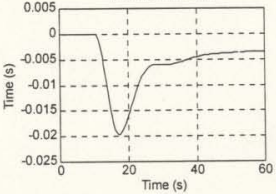

(b) Area Control Enor (ACE)

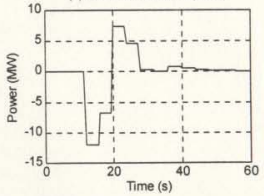

(d) Mechanical Power, Load Power \& Reference Setpoint

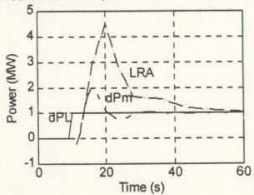

Figure 3.6 Increase in Bias Factor for the Single Machine System 
The last simulation set utilizes a more complex power system model as shown in Figure 3.7. This system consists of two AGC-controlled hydro generating units (these units have been modeled using the same parameters) and a non-AGC controlled thermal generating unit. All load changes are met by the hydro units and are shared equally between them. The thermal unit contributes to the load demand initially via primary control but AGC returns its MW generation to its scheduled value. As for the single machine system, this system is subjected to a 1-MW step load increase, and the bias factor changes following a load change for two of the three simuiations.

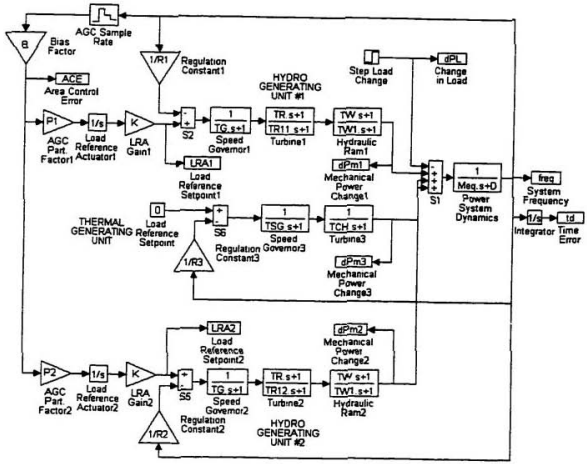

Figure 3.7 Multi-Machine Power System Model 
Figure 3.8 shows the base case simulation results for the multi-machine power systern model. Following the 1-MW step load change shown in Figure 3.8(d), the three generating units in the system respond by adjusting their MW outputs $\left(\mathrm{dP}_{\mathrm{m} 1}, \mathrm{dP}_{\mathrm{m} 2}\right.$ and $\mathrm{dP}_{\mathrm{mi}}$ are the $\mathrm{MW}$ outputs of the two hydro units and the thermal unit, respectively) via primary control. Shortly after primary control action, the AGC process reacts to the frequency change via the ACE to return the system frequency to $60 \mathrm{~Hz}$, and to reallocate generation among the units. This is accomplished by readjusting the generation of the AGC-controlled hydro units to supply the load change allowing the thermal unit MW generation to be returned to its original scheduled output. In addition, the time error reaches a steady-state value of approximately $-0.85 \mathrm{~ms}$, as shown in Figure 3.8(c).

(a) System Frequency
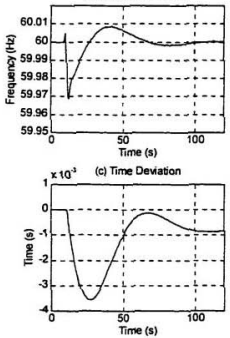

(b) Area Cortrol Enor (ACE)

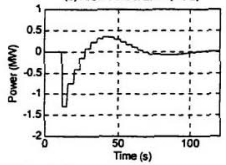

(d) Mectarical Poner. Load Power \& Reference Setooint

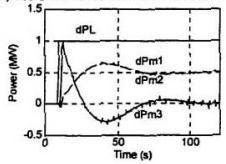

Figure 3.8 Simulation Data for Multi-Machine System with $B=25 \mathrm{pu} \mathrm{MW/0.1} \mathrm{Hz}$ 
Figures 3.9 and 3.10 illustrate the simulation results for a decrease and an increase in the bias factor following the load change, respectively. In Figure 3.9, the bias factor has been decreased from $25 \mathrm{pu} \mathrm{MW/0.1} \mathrm{Hz}$ to $15 \mathrm{pu} \mathrm{MW} / 0.1 \mathrm{~Hz}$. As with the single machine simulations, this change takes effect 2 seconds following the change in load. The results show that the $\mathrm{ACE}$ has decreased in magnitude yielding a steady-state time error of about $-1.5 \mathrm{~ms}$ from $-0.85 \mathrm{~ms}$ for the base case simulation. In Figure 3.10 , the bias factor is increased to $35 \mathrm{pu} \mathrm{MW/0.1} \mathrm{Hz}$. In this case, the ACE has increased but the steady-state time error has decreased to $-0.29 \mathrm{~ms}$.

(a) System Frequency

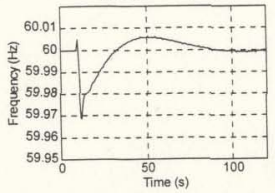

(c) Time Deviation

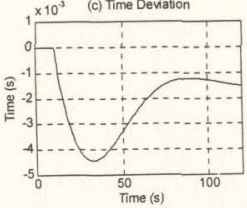

(b) Area Control Error (ACE)

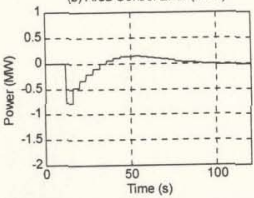

(d) Mecharical Power, Load Power \& Reference Setpoint

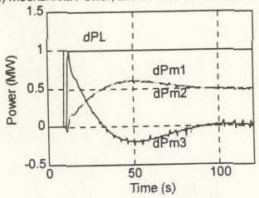

Figure 3.9 Decrease in Bias Factor for the Multi-Machine System 
(a) System Frequency

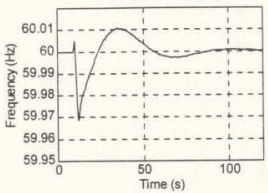

(c) Time Deviation

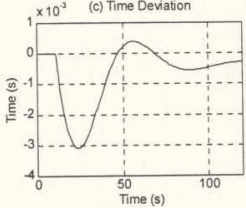

(b) Area Control Error (ACE)

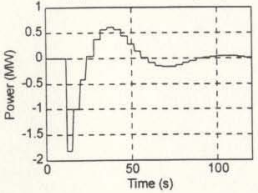

(d) Mecharical Power, Load Power \& Reference Setpoint

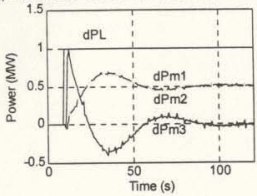

Figure 3.10 Increase in Bias Factor for the Multi-Machine System

The simulations performed in this section demonstrate three important results. First, the effect of the automatic generation control process is exemplified with the first two simulations. Following a 1-MW step load change and with only primary control, the single generating unit supplied the required MW to meet the load demand but a steadystate frequency error remained. This error is corrected by adding the secondary control process that adjusts the load reference setpoint of the unit's speed governor. The effect is to readjust the MW output of the generating unit and return system frequency to its scheduled value.

Second, the effect of changing the bias factor for both the single and multimachine systems is shown using a 1-MW step load change, and a decrease and increase in the base static value of $25 \mathrm{pu} \mathrm{MW} / 0.1 \mathrm{~Hz}$. The steady-state time error in each case 
increased and decreased, respectively. This demonstrated that the proper selection of the bias factor can improve system regulation of frequency error, and hence decrease the accumulation of time error in an isolated power system. Although some additional control, in the form of an increased ACE, was necessary to achieve the decrease in time error, the small increase in unit control realized in this example will not cause increased wear and tear on the generator. This is evident since the increased control was in the same direction as the generation movement for the base case simulation. If the unit control had been in the opposite direction, the unit would have to change the direction of its momentum (causing it to slow down while it is in the process of increasing the power output) and hence would increase the wear and tear on the unit.

Finally, the multi-machine simulations demonstrated how secondary control readjusts the MW output of AGC-controlled generating units to meet the load demand of the system while maintaining the MW outputs of those units not controlled by AGC. Initially, the non-AGC controlled thermal unit responded via primary control to the change in load but its generation was returned to its scheduled value following the secondary control action of AGC. This enabled the AGC-controlled hydro units to readjust their generations while the thermal unit responded to the initial disturbance of the load change.

\subsection{NLH Isolated Power System Model}

The Newfoundland and Labrador Hydro Power System operates isolated from the North American Interconnected Power System. Because of this isolation, the existing 
operating conditions are unique when compared to the interconnected power system operating conditions of the remainder of North America. This is due primarily to the fact that the NLH must perform all active power and frequency control for the island's power system. Since there is no tie-line power interchange as for the conventional AGC control process, the frequency fluctuations, and hence the time accumulations, are greater.

To model the NLH Power System, some simple assumptions regarding the complex dynamics of an actual power system were required. These assumptions enabled complex components and functions to be represented with simple control models. In addition, detailed information describing components of the power system and its existing operating condition were provided by NLH from its Dispatcher Training Simulator (DTS). This information included various power system models and equipment parameters, the MW generation, and incremental cost curves of all generating units. The mathematical models and qualitative descriptions given in Chapter 2 were used to model the dynamics of the NLH power system with the exception of a few components that were given in more detail in NLH DTS documents. Since this data is proprietary, only the basic concepts will be presented here.

\subsubsection{Simulation Assumptions}

To simplify the complex dynamics associated with the operation of an actual power system, some simple assumptions were necessary. These assumptions are common when simulating power system dynamics in large system studies. The assumptions made include: 
- Common frequency throughout power system

- Actual NLH generation was used as the load change for the model input;

- No time error correction;

- Effects of transmission lines and associated data transmission delays were neglected;

- EDC basepoint assumed constant for length of simulation

- No operator control of non-AGC generating units

- Speed governor deadbands are not included

These assumptions facilitated the development of individual component models and the overall system model.

\subsubsection{Simulation Model}

The NLH power system simulation model was developed and implemented in SIMULINK by combining the mathematical models and qualitative descriptions for the various power system components described previously in this document. This included models for the synchronous generator, speed governors, turbines, unit controllers and the automatic generation control process. A portion of the overall system model is shown in Figure 3.11, and the sub-components are described and illustrated in the following paragraphs. In total, 17 generating units were modeled including 12 hydro units, 3 thermal units and 2 gas turbine units. A list of each generating unit with its generating capacity and other relevant information is given in Appendix A.

The lower right hand corner of Figure 3.11 shows the block diagram model of the synchronous generator, represented by the M Calculation, Frequency Calculation and 11 
(integrator) blocks. This is used to determine the frequency change resulting from the mismatch between the load demand (including frequency and non-frequency dependent components) and the total on-line generation. This process involves the calculation of the inertia constant, which is dependent on what generating units are on-line, and the determination of the system frequency.

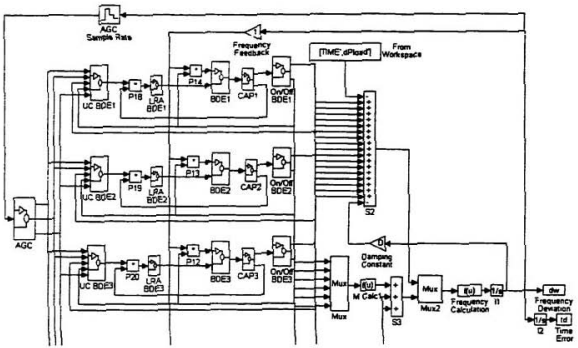

Figure 3.11 Overall NLH Power System Model

The CAP blocks for each unit are used to model the MW capacity of the individual generating units. This prevents the turbine from exceeding its maximum MW output. The input to this component is the turbine mechanical power change. The top output is the turbine mechanical power change, which is equal to the input if the MW capacity has not been exceeded, and is zero if the unit has reached its capacity limit and the turbine attempts to increase the unit generation. The lower output line is a status 
indicator which blocks the UCE signal from reaching the load reference actuator if the MW capacity has been exceeded and an increase in generation is requested.

The On/Off blocks are used to bring the generating units on/off-line according to the generation schedule as determined by the actual NLH generation data. The input to this block is the mechanical power change of the turbine. The top output is equal to the input if the unit is on-line, and is zero if it is off-line. The lower output line is the status of the unit, that is, whether it is on-line (1) or off-line $(0)$. This information is used primarily to calculate the system inertia constant.

The turbine models used in the implementation of the NLH power system are based on the general model of turbine systems given by the Task Force on Overall Plant Response [14]. The model is shown in Figure 3.12 with the interpretation of parameters applicable to NLH generating units provided in Table 3.2 .

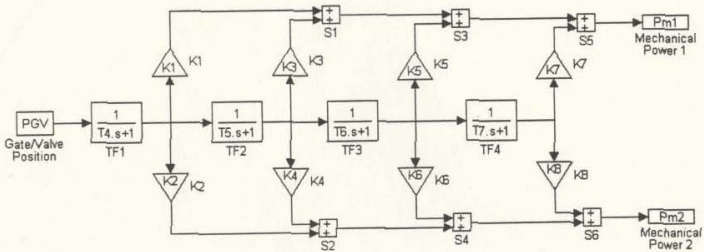

Figure 3.12 General Model for Turbine Systems

Depicted in Figure 3.13 is the speed governor/turbine model for the thermal generating unit used in the NLH power system model. Figures 3.14 and 3.15 show the model subsystems for the governor, pressure and fuel dynamics, and the steam turbine 
dynamics, respectively. The speed governor/turbine model for the hydro unit is shown in

Figure 3.16. These turbine models were based on the general turbine model given above. The NLH system also utilizes two gas turbines and the model used to simulate its dynamics and its speed governor is illustrated in Figure 3.17.

Table 3.2 Interpretation of Parameters Used in the General Model for Turbines

\begin{tabular}{|l|l|}
\hline \multicolumn{1}{|c|}{ SYSTEM DESCRIPTION } & \multicolumn{1}{|c|}{ PARAMETERS } \\
\hline \multirow{5}{*}{ Single Reheat Steam Turbine } & Time Constants: \\
& $\mathrm{T}_{4}=\mathrm{T}_{\mathrm{CH}}$ \\
$\mathrm{T}_{5}, \mathrm{~T}_{6}, \mathrm{~T}_{7}=0$ \\
\cline { 2 - 3 } & Fractions: \\
& $\mathrm{K}_{1}=\mathrm{F}_{\mathrm{HP}}, \mathrm{K}_{3}=\mathrm{F}_{\mathrm{IP}}, \mathrm{K}_{5}=\mathrm{F}_{\mathrm{LP}}$ \\
& $\mathrm{K}_{2}, \mathrm{~K}_{4}, \mathrm{~K}_{6}, \mathrm{~K}_{7}, \mathrm{~K}_{8}=0$ \\
\hline \multirow{5}{*}{ Hydro Turbine } & Time Constants: \\
\cline { 2 - 3 } & $\mathrm{T}_{5}=\mathrm{T}_{W} / 2$ \\
& $\mathrm{~T}_{4}, \mathrm{~T}_{6}, \mathrm{~T}_{7}=0$ \\
\cline { 2 - 3 } & Fractions: \\
\cline { 2 - 3 } & $\mathrm{K}_{1}=-2, \mathrm{~K}_{3}=3$ \\
\hline & $\mathrm{K}_{2}, \mathrm{~K}_{4}, \mathrm{~K}_{5}, \mathrm{~K}_{6}, \mathrm{~K}_{7}, \mathrm{~K}_{8}=0$ \\
\hline
\end{tabular}




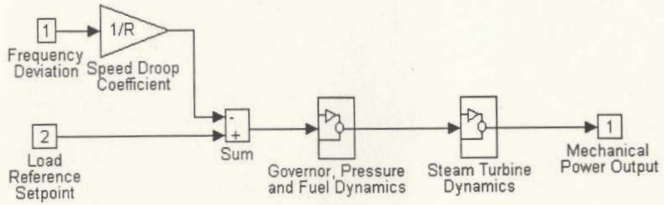

Figure 3.13 Thermal Generating Unit Model

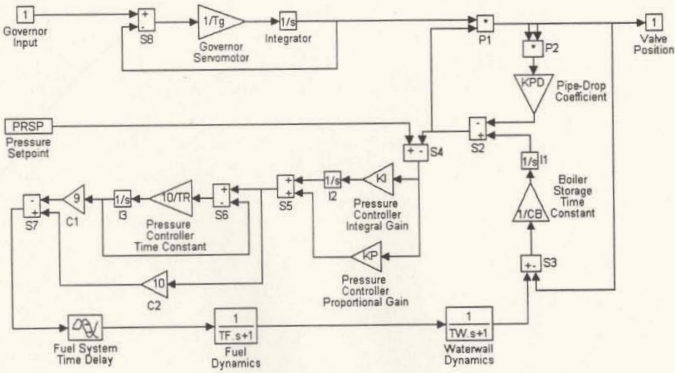

Figure 3.14 Governor, Pressure and Fuel Dynamics for the Thermal Generating Unit 


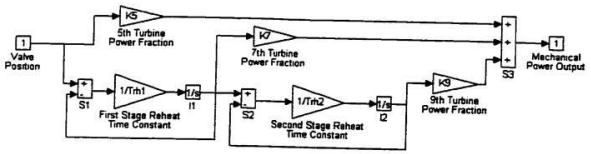

Figure 3.15 Steam Turbine Dynamics for the Thermal Generating Unit

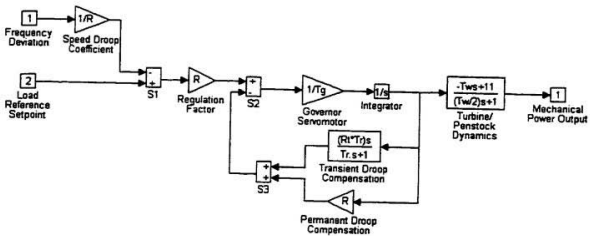

Figure 3.16 Hydro Generating Unit Model

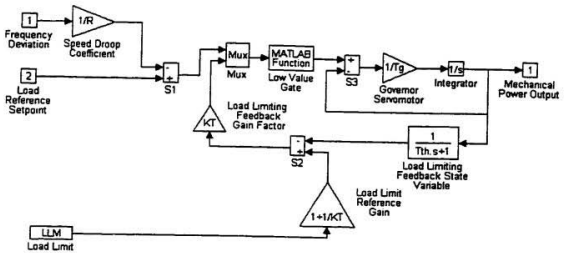

Figure 3.17 Gas Turbine Generating Unit Model 
The unit controller and load reference actuator are illustrated in Figure 3.18. The UCE Accumulator process block near the top center of the diagram determines the unit control error based on the inputs shown on the left side of the diagram. The UCE is only output to the load reference actuator if the ACE and UCE have the same sign and if the accumulated UCE exceeds the UCE deadband. This is determined by the Unit Control? block. The load reference actuator is basically a feedback loop similar to that shown in Figure 2.2 for the speed governor dynamics.

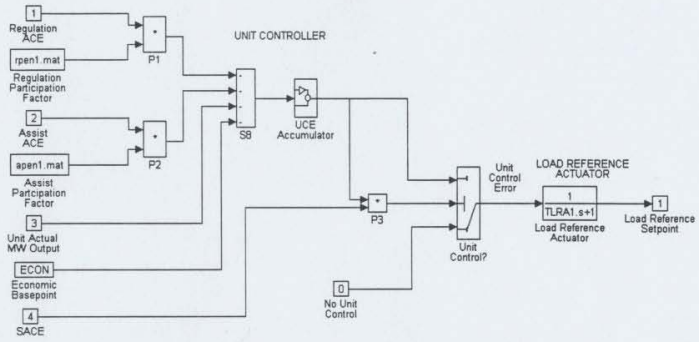

Figure 3.18 Unit Controller and Load Reference Actuator Model

The AGC control system is depicted in Figure 3.19. This process involves determination of the ACE using the frequency deviation and the bias factor. The raw $\mathrm{ACE}$ is then filtered to remove any fast variations in its magnitude. The smoothed or filtered $\mathrm{ACE}$ is subsequently divided into regulation (RACE) and emergency assist (EACE) components. This is accomplished using the process shown on the right side of the diagram. Note that the regulation deadband is smaller than the assist deadband. This 
means that the EACE is calculated only when the ACE is very large. During normal operation, the EACE is typically zero.

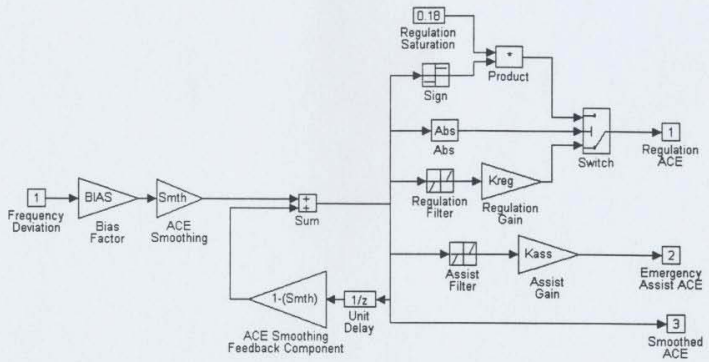

Figure 3.19 Automatic Generation Control Model

\subsection{Summary}

This chapter has discussed computer simulations of simple and complex power systems with automatic generation control. Using computer simulation techniques, the AGC process was analyzed for varying bias factors for single- and multi-machine isolated power systems. Section 3.2 introduced and described the software tool used for the simulations. These tools provided the modeling, simulation, and graphical analysis capabilities necessary for simulating the power systems considered in this research. SIMULINK provided the modeling capability by allowing the implementation of the 
block diagram models of the power systems. MATLAB provided the computational and graphical tools for analyzing the simulation results.

Section 3.3 presented models and simulations results for two power systems: a single machine system with a hydro generating unit; and a multi-machine system with two AGC-controlled hydro generating units and a single non-AGC controlled thermal generating unit. The simulation results showed the effect AGC has on the frequency regulation. It was shown that the frequency offset that remains following primary control can be regulated to zero using the secondary control action of adjusting the load reference setpoints of the generating unit speed governors. In addition, the effect of changing the bias factor on the frequency regulation as a result of a change in some characteristic of the power system, in this case a change in the load demand, was illustrated.

In Section 3.4, the dynamic model of an actual power system was presented. Simplifying assumptions were listed that enabled some functions such as operator control of generating units and economic dispatch to be neglected. The SIMULINK block diagrams of subsystems in the power system model and a description of their operation were provided. Each of these subsystem models were implemented in SIMULINK and thoroughly tested for their proper operation. 


\section{Chapter 4}

\section{Investigation of Dynamic Bias Factors}

\subsection{Introduction}

One of the main objectives of this research is to investigate the use of a dynamic bias factor in the AGC process. Presently, power utilities utilize a static value that remains the same throughout the year, usually for a wide variety of operating conditions. These operating conditions, which are continuously changing, include a variation in the peak load, the mix of on-line generating unit types, and a mix in the number and type of units under AGC control. Since the SRC depends on these system characteristics, and tends to be highly variable and non-linear, estimating it with a linear, static bias factor leads to unnecessary generation movement in order to regulate frequency. Varying the bias factor based on some or all of these system characteristics would improve the overall system regulation.

The first four sections of this chapter describe the proposed bias factor calculation methods. Based on the system characteristics introduced in the preceding paragraph, the bias factor is varied and used in the ACE calculation. This "dynamic ACE" is then used in the AGC process to improve system regulation. The next section describes the simulation procedure used in the investigation of the AGC process. Using the assumptions and simulation models given in Chapter 3, a base case, which utilizes the 
static bias factor of $15 \mathrm{MW} / 0.1 \mathrm{~Hz}$, is simulated for a variety of operating conditions (varying load demand and on-line generation). Next, the model is simulated for the same operating conditions using the bias factor calculation methods. Note that these methods yield large bias values as compared to the static value of $15 \mathrm{MW} / 0.1 \mathrm{~Hz}$. As a result, each dynamic bias factor scheme scales the bias value to the same order of magnitude as the static value before each is used in the ACE calculation. This is necessary since the large values give unsatisfactory results.

\subsection{Bias Factor Calculation Method \#1}

The first calculation method to determine the dynamic bias factor is based on the expression for the SRC given by Eq. (2.28). This equation uses the actual MW generations and speed droop settings for each on-line generating unit, and is given in units of per unit. Converting to units of $\mathrm{MW} / \mathrm{Hz}$ gives a bias factor $\mathrm{B}$ in the form

$$
\mathrm{B}=\frac{1}{f} \sum\left(\frac{\mathrm{P}_{\mathrm{Gi}}}{\mathrm{R}_{i}}\right)+\frac{\mathrm{D}}{f} \sum \mathrm{P}_{\mathrm{Gi}}
$$

where $P_{G i}=M W$ power output of generating unit $i$,

$$
\begin{aligned}
& f=\text { scheduled frequency }(60 \mathrm{~Hz}) \text {, and } \\
& \mathrm{D}=\text { load damping constant }(1 \%) .
\end{aligned}
$$

This bias factor calculation is performed on a 30-minute interval, which corresponds to the calculation interval of the economic dispatch function. 


\subsection{Bias Factor Calculation Method \#2}

The second calculation method utilizes the annually determined static bias factor value to calculate the dynamic bias factor. This method adjusts the static bias factor based on the total system load and the forecasted annual peak load. For calculation purposes, it is assumed that the total system load is equal to the total system generation since this quantity is readily available. So the dynamic bias factor, which is again calculated on a 30 -minute interval, is

$$
\mathrm{B}_{\text {dymamic }}=\mathrm{B}_{\text {static }} \times\left(\frac{\text { Peak Load }_{\text {year }}}{\text { Load }_{\frac{l}{2} \text { hour }}}\right)
$$

In this method, the ratio of the peak and the 30 -minute loads adjusts the static bias factor to take into account the highly variable load conditions experienced by the NLH power system throughout the year. The annual forecasted peak load used in this calculation is $1260 \mathrm{MW}$.

\subsection{Bias Factor Calculation Method \#3}

The third calculation method is again based on Eq. (2.28) but results in a different bias factor value only when the system on-line generator configuration changes. In addition, the generating capacity of each unit is utilized instead of their actual MW generation since at the change of system generator configuration, the unit coming on-line or going off-line has zero generation. Hence, the actual MW generation would have no effect on the bias factor calculation. The resulting bias factor calculation is 


$$
\mathrm{B}=\frac{1}{f} \sum\left(\frac{\mathrm{u}_{\mathrm{i}} * \mathrm{P}_{\mathrm{i}}}{\mathrm{R}_{\mathrm{i}}}\right)
$$

where $u_{i}=1(0)$ when generating unit $i$ is on-line (off-line), and

$P_{i}=$ the power generating capacity of unit $i$.

In this case the $\mathrm{D}$ term is neglected since it has little effect on the overall bias factor value when the generating capacity is used in the calculation.

\subsection{Bias Factor Calculation Method \#4}

The fourth calculation method utilizes the concepts developed in calculation methods \#2 and \#3. In this case, the bias factor in Eq. (4.2) is recalculated when the system generator configuration changes as opposed to a 30 -minute interval. So

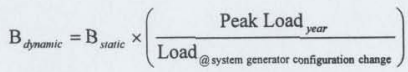

This calculation method takes into account the annual peak load and the system generator configuration (on-line generation), both of which are important in determining the SRC.

\subsection{Simulation Procedures}

The simulation model presented in Section 3.4 for the NLH power system was used to investigate the bias factor calculation methods introduced in this chapter. This model was implemented in SIMULINK, and the simulation results analyzed in the MATLAB workspace. Using actual NLH system data (including generating unit MW 
outputs, system frequency, SACE and time error), the simulation model was tested by comparing the simulation results using the base case bias factor of $15 \mathrm{MW} / 0.1 \mathrm{~Hz}$ with actual system data. Note that the accuracy of the simulation model and results are limited primarily by the assumptions listed in Section 3.4.1. Taking this into account, the base case simulation results were found to closely matched the actual data.

The first step in the investigation process required the simulation of the base case with the static bias factor. The simulation process was facilitated by using simple MATLAB programs that inputted the required data into the MATLAB workspace, started the simulation, processed the output data, and saved it in MATLAB data files for further processing and plotting. A sample MATLAB program used for this process is given in Appendix B. Unit MW generations, time error plots, and frequency profiles were then compared to the corresponding actual NLH data to verify the simulation results. Subsequent simulations involved the dynamic bias factor calculations. Following the five simulations, the results were compared to the base case and with each other. Simulation parameters, such as the simulation integration step and AGC sample rate, are listed in Appendix B.

\subsection{Summary}

In this chapter, the calculation methods used to determine the dynamic bias factor are introduced. The first two methods use the total load to calculate the bias factor on a 30-minute interval. Calculation method \#l uses the generation of all on-line generating 
units. Calculation method $\# 2$ uses the ratio of the annual forecasted peak load and the total load.

The last two methods calculate the bias factor based on a change in the on-line generator configuration. Calculation method \#3 is similar to method \#l except for the frequency of bias factor calculation and the use of the generating capacity of the unit as opposed to the actual MW output. Calculation method \#4 is identical to method \#2 except for the calculation interval that now is performed when a change in the on-line generator configuration occurs.

The simulation procedure was a relatively simple process. MATLAB programs were written to facilitate the input of system data, the start of simulations, and the saving of output data. In addition, data was further processed and plotted using other simple MATLAB programs. 


\section{Chapter 5}

\section{AGC Performance Evaluation}

\subsection{Introduction}

Overall system performance is an important subject in the day-to-day operations of an electrical power system. Good performance is reflected in the economics of the power system operation by decreasing operating costs while increasing revenues and the life expectancy of equipment. This area is increasingly important for an isolated power system that cannot rely on other control areas to aid in meeting the load demand (such as in emergency situations) and for frequency control. It is the function of the Energy Management System to provide this and other control functions to maintain good performance of the electrical power system.

Automatic generation control is one control method that is utilized which can improve the overall performance of a power system. As discussed in the previous chapters, time error and unit control error (UCE) are two criteria upon which the performance can be judged for the isolated system. Time error is a measure of the frequency regulation capabilities of a control area and is representative of the "closeness" of the system frequency to $60 \mathrm{~Hz}$. If the time error is kept small (equating to minimal time error accumulation), this would be an indication that the frequency error is being regulated to zero effectively by the AGC process. Unit control error provides a measure 
of the movement of the load reference setpoint of generating unit speed governors. If the unit control is minimized or does not increase significantly, as indicated by the UCE, then improved regulation is achieved with little or no increase in the movement of on-line generation to meet the load demand.

The first section in this chapter presents the input data and simulation results, in graphical form, for the NLH isolated power system model simulations. Various operating conditions were used to represent the different load demands and on-line generation configurations that occur throughout the year. Simulations were carried out for the base case with a static bias factor of $15 \mathrm{MW} / 0.1 \mathrm{~Hz}$ (this represents the present NLH system), and for the four dynamic bias factor calculation methods.

The second section provides an analysis and discussion of the simulation results presented graphically in the first section. The main focus will be the comparison of time error plots and unit control errors for the different bias factor schemes. This will aid in the determination of an optimal scheme for dynamic bias factor calculation. Note that since the operation of the power system is very complex it is difficult to define a specific index by which the system performance may be measured. As a result, it was deemed necessary to use a set of system quantities (time error and UCE) to judge the benefits of one control method over another.

\subsection{Simulation Results}

This section presents the simulation results for the NLH isolated power system simulation model for various operating conditions. The conditions used vary primarily 
with load level and on-line generation configuration. The load for five 24-hours periods (starting at 12:00:00 $\mathrm{AM}$ and ending at 11:59:59 $\mathrm{PM}$ ) is utilized for input to the simulation model. Those considered for illustration purposes in this report include: Thursday, October 17, 1996; Friday, April 4, 1997; Thursday, June 26, 1997; Friday, July 11, 1997; and Saturday, July 12, 1997. All but the July 1997 data sets have a mixture of thermal and AGC-controlled hydro generating units on-line to meet the load demand, while the July 1997 data sets consist of only AGC-controlled hydro units. In addition, the June and July loads have significantly lower peak loads (approx. $600 \mathrm{MW}$ ) as compared to the other data sets (approx. $900 \mathrm{MW}$ ). For each load period, the following figures present the load demand, the dynamic bias factors, the time error plots, and the mean UCE sums. The UCE sums are obtained by adding sampled UCE values for each unit over a 10-minute interval.

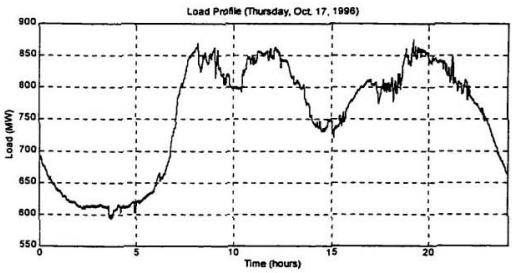

Figure 5.1 Load Profile for October 17, 1996

Figure 5.1 depicts the load demand for October 17, 1996. The general shape of the curve remains the same for the majority of the days with differences mostly between 
the weekdays and the weekends. This difference is primarily with the time at which the morning load pickup occurs, the fluctuation of the load throughout the day, and when the load decreases to its nighttime MW low.

Figure 5.2 shows the bias factor determined using the dynamic calculation methods presented in the previous chapter. The general shape of the curves typify the calculation method. The bias factor for method \#1 tends to follow the shape of the load demand while method $\# 2$ tends to follow its inverse (that is, the greatest bias value occurs at the lowest $\mathrm{MW}$ ). Methods \#3 and \#4 vary with the on-line generation configuration. The bias factor determined by method $\# 3$ has its largest value when the on-line generation configuration has the most units on-line to meet the load demand. This typically occurs at the greatest load demand periods. Method \#4, on the other hand, typically has its highest bias value when the least number of units are on-line to meet the MW demand.

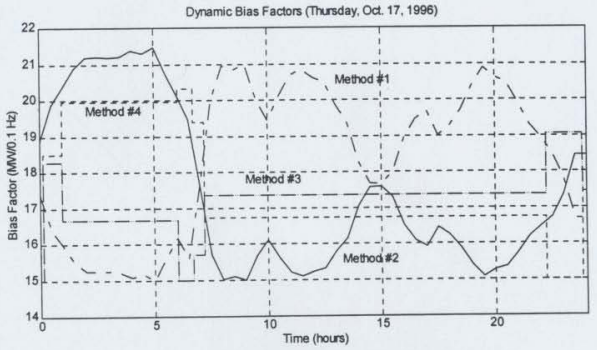

Figure 5.2 Dynamic Bias Factors for October 17, 1996 


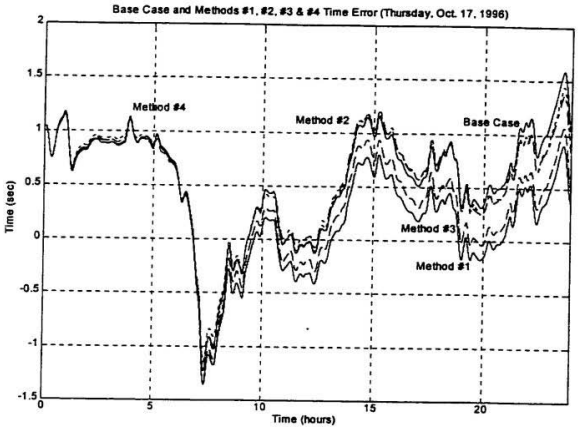

Figure 5.3 Time Error for October 17, 1996

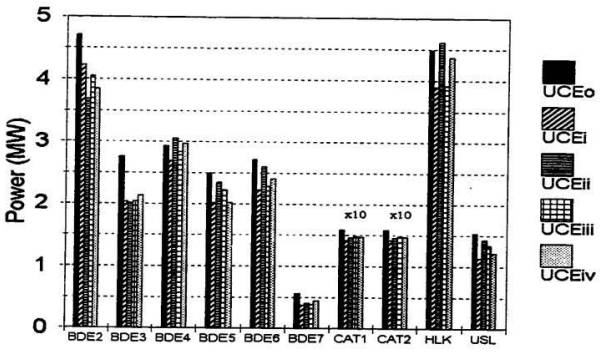

Figure 5.4 Mean UCE Sum for October 17, 1996 


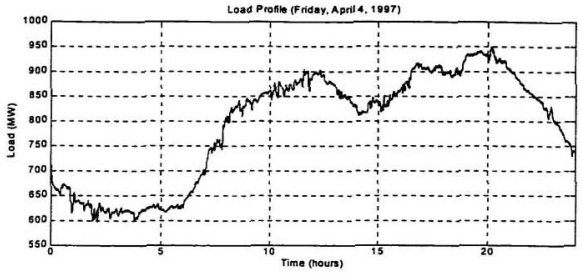

Figure 5.5 Load Profile for April 4, 1997

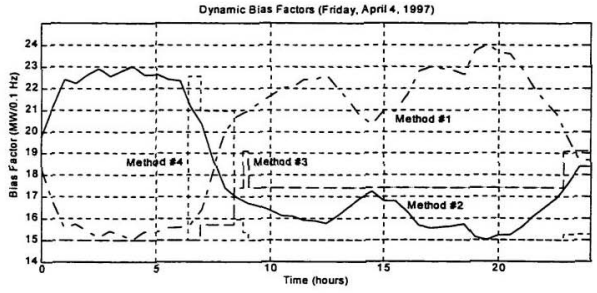

Figure 5.6 Dynamic Bias Factors for April 4, 1997 


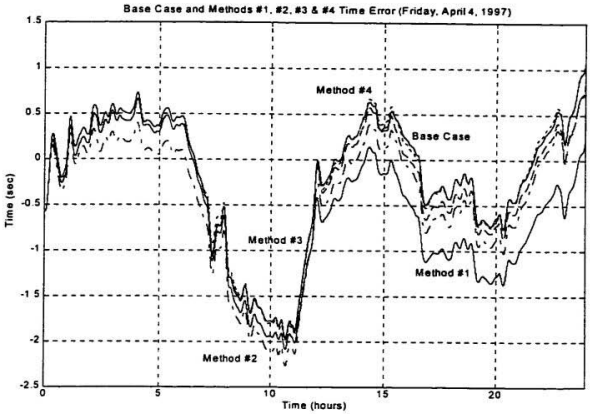

Figure 5.7 Time Error for April 4, 1997

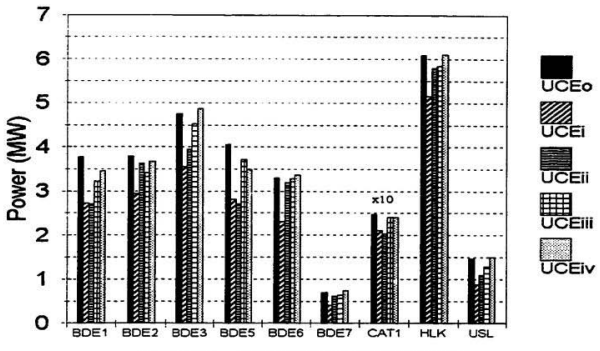

Figure 5.8 Mean UCE Sum for April 4, 1997 


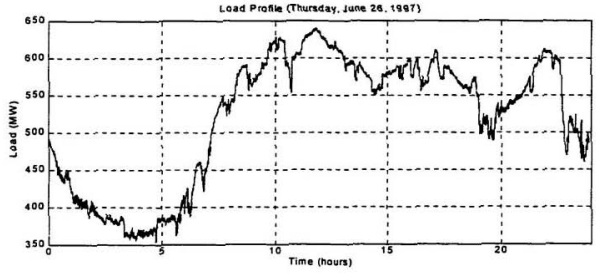

Figure 5.9 Load Profile for June 26, 1997

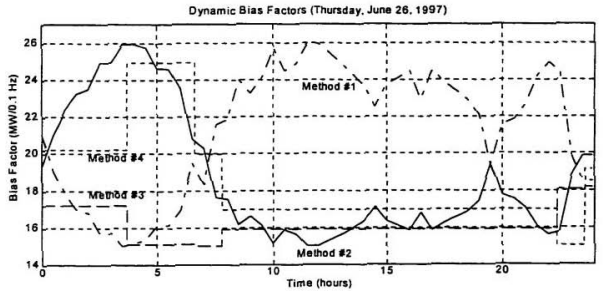

Figure 5.10 Dynamic Bias Factors for June 26, 1997 


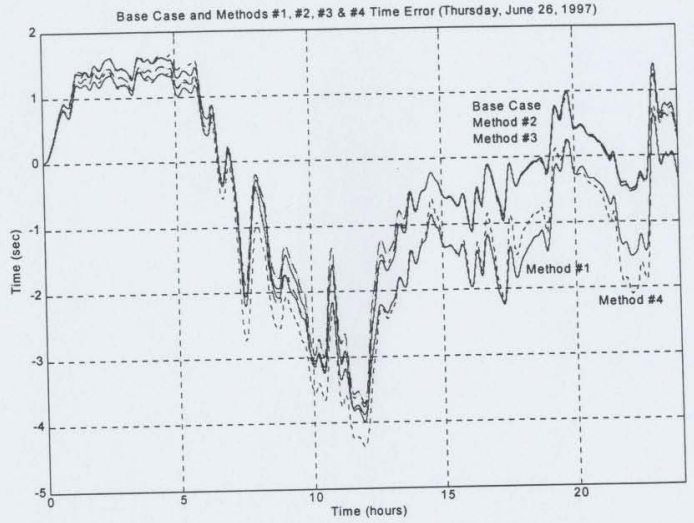

Figure 5.11 Time Error for June 26, 1997

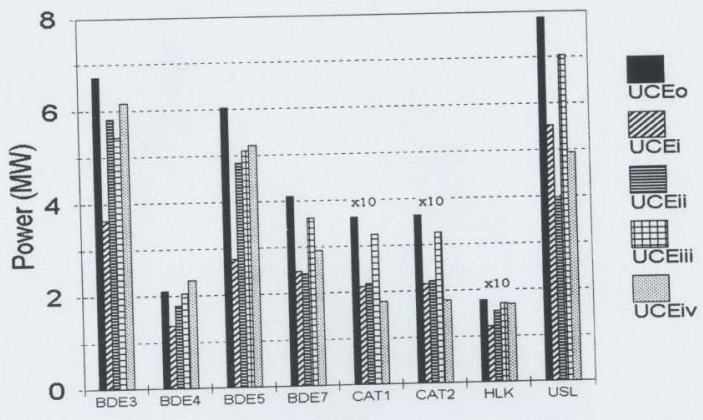

Figure 5.12 Mean UCE Sum for June 26, 1997 
Load Profile (Friday, July 11, 1997)

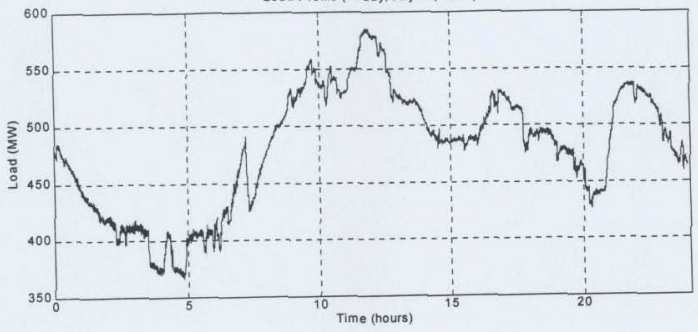

Figure 5.13 Load Profile for July 11, 1997

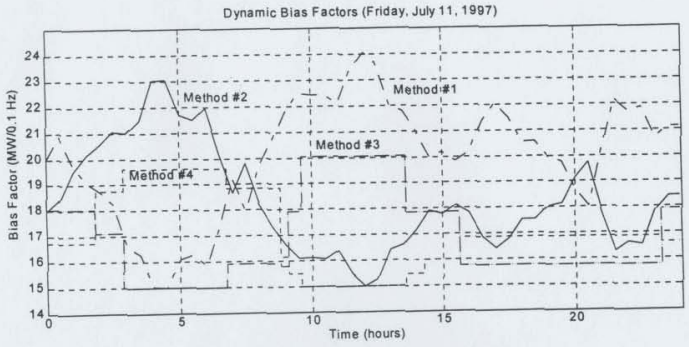

Figure 5.14 Dynamic Bias Factors for July 11, 1997 


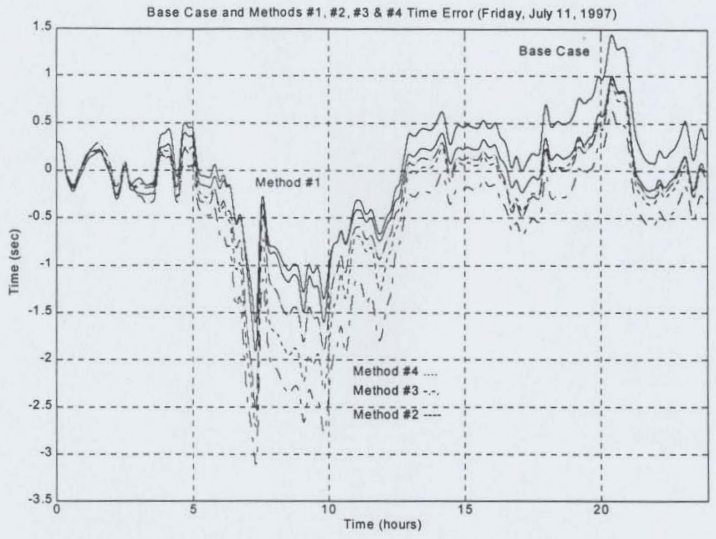

Figure 5.15 Time Error for July 11, 1997

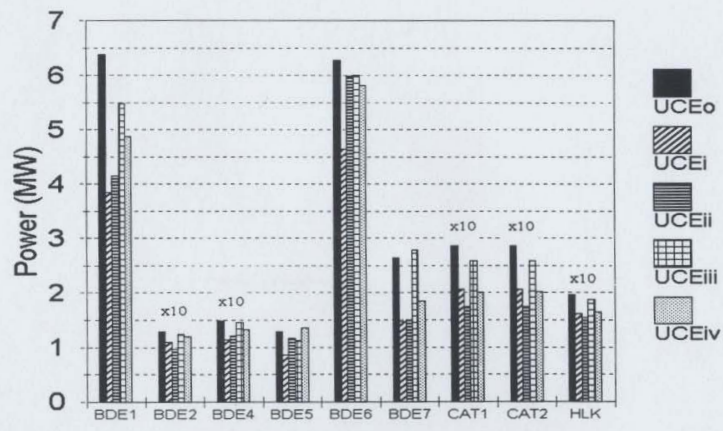

Figure 5.16 Mean UCE Sum for July 11, 1997 


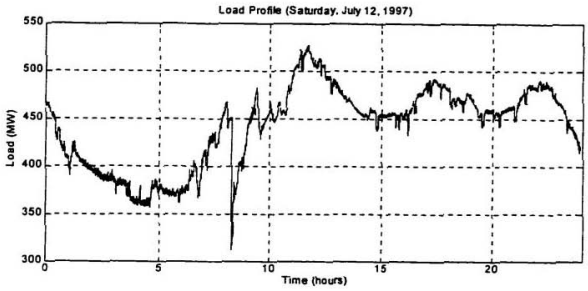

Figure 5.17 Load Profile for July 12, 1997

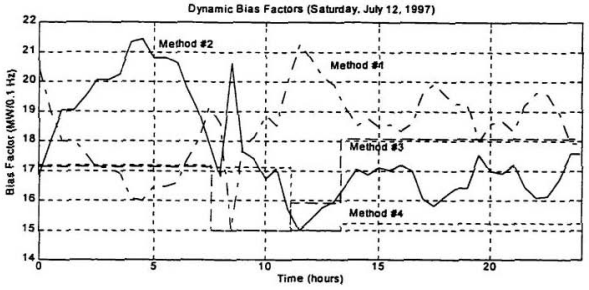

Figure 5.18 Dynamic Bias Factors for July 12, 1997 


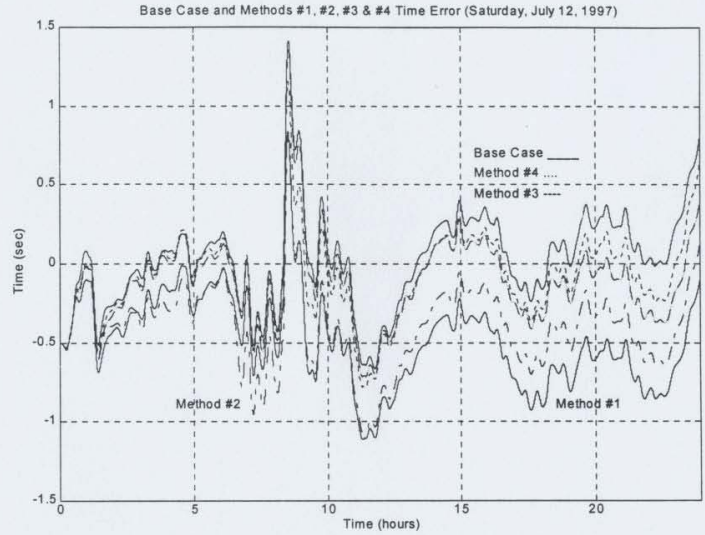

Figure 5.19 Time Error for July 12, 1997

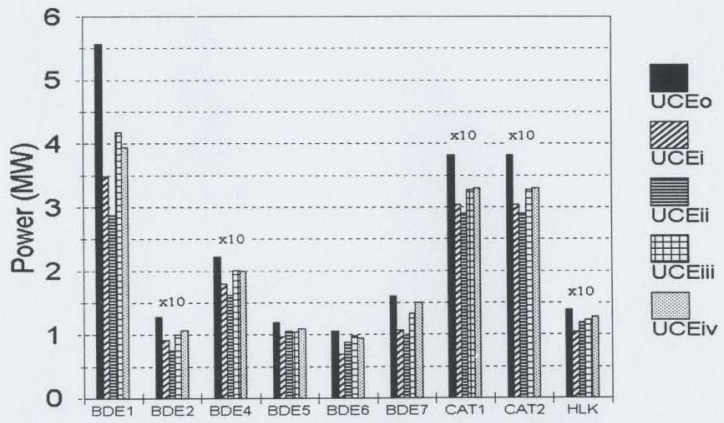

Figure 5.20 Mean UCE Sum for July 12, 1997 


\subsection{Analysis and Discussion of Results}

Time error and UCE are the primary performance measures utilized in the investigation of the dynamic bias factor. Using these quantities and their graphical representations, an optimal calculation method will be determined. Other quantities such as the system frequency and the ACE can also be used but these are merely extensions of the time error and UCE, respectively (as described previously in Chapter 3). In addition, their graphical representations are difficult to interpret when making comparisons between the base case and dynamic bias factor simulations. This section will qualitatively compare the time error and mean UCE sum plots illustrated in Section 5.2 for each of the five data sets. Quantitative analysis does not provide an adequate measure of the performance of the power system with respect to the dynamics associated with the AGC control process. Hence, graphical means will be primarily utilized in comparing the dynamic bias factor methods.

For the October 17 input data, the load varies from a minimum value of $592 \mathrm{MW}$ (3:45 $\mathrm{AM})$ to the peak value of $876 \mathrm{MW}(7: 13 \mathrm{PM})$. In this case, method $\# 1$ yields the lowest time error as compared to the other four simulations (base case and the other three calculation schemes). This is evident since the time error varies less from the zero second mark for more of the 24-hour test period. As a result, the total time error accumulated during this period is less than for the other simulations. Correspondingly, except for unit's BDE2 and BDE3, the mean UCE sum for the generating units is lowest among the five simulation tests. Note that method $\# 3$ has an accumulated time error that is just 
slightly more than that for method \#1 and also has mean UCE sum values that are low compared to the base case.

For the April 4 input data, the load varies from a minimum value of $596 \mathrm{MW}$ (2:08 AM) to the peak value of $951 \mathrm{MW}(8: 09 \mathrm{PM})$. In this case, method $\# 3$ results in the lowest time error response. In addition, the mean UCE values for the on-line generating units during the test period show no significant increase over the base case.

For the June 26 input data, the load varies from a minimum value of $353 \mathrm{MW}$ (4:44 AM) to the peak value of $641 \mathrm{MW}(11: 48 \mathrm{AM})$. For this operating condition, method \#3 is again the method that yields the best response although it has only slight improvements in the amount of accumulated time error when compared to the other four simulations. These improvements are accompanied by decreases in the mean UCE values meaning less secondary control is achieved.

For the July 11 input data, the load varies from a minimum value of $366 \mathrm{MW}$ (4:51 AM) to the peak value of $585 \mathrm{MW}(11: 52 \mathrm{AM})$. For this operating condition, the thermal units are off-line for maintenance purposes. This means that the hydro units have the sole responsible of both primary and secondary control. The simulations using methods \#1 and \#3 both yield low accumulated time errors. During the morning pick-up period, between 5 and $10 \mathrm{AM}$, method $\# 1$ provides the better time error response. Method \#3 betters method \#1 during the afternoon/evening period when the load is steadier. Method \#1 again outperforms the other calculation methods with respect to the mean UCE sums.

For the July 12 input data, the load varies from a minimum value of $312 \mathrm{MW}$ (8:18 $\mathrm{AM})$ to the peak value of $528 \mathrm{MW}(11: 41 \mathrm{AM})$. This operating condition is very 
similar to the previous but the load demand is slightly reduced and is steadier in the afternoon/evening periods. In this case, method \#3 provides the most improved time error and UCE. The time error accumulation during both the morning pick-up and the afternoon/evening period is the lowest using this method.

The simulation results depicted in Section 5.2 and discussed in this section show methods \#1 and \#3 to yield the lowest time error accumulation and lower secondary control as compared to the base case. These methods both utilize Eq. (2.28) and differ only in the calculation interval. In both cases, the bias factor tends to follow the load demand. For method \#1, the bias factor is essentially a scaled version of the load demand. For method $\# 3$, the bias factor increases as more units are brought on-line to meet the increase in load demand.

Method \#1 recalculates the bias factor every 30-minutes while method \#3 recalculates when the on-line generation configuration changes. In both cases, the bias factor tends to follow the load demand. This method results in good time error responses while requiring infrequent bias factor calculations. Using method \#1, the bias factor is calculated 48 times during the 24 -hour test periods while for method \#3, the number of calculations drops to an average of about 7 times per 24-hour period. This reduction in calculation rate has little effect on the simulation results.

\subsection{Summary}

As indicated in the previous section, an overall decrease in the amount of accumulated time error with no corresponding increase in unit control represents a control 
process that improves the overall system regulation. The lower time error indicates a frequency response that stays closer to the scheduled frequency. The decrease in unit control indicates that less secondary control is required to meet the load demand. The result is increased revenues and less wear-and-tear on the generating units, respectively.

Close inspection of the time error plots for the five data sets presented in Section 5.3 shows some improvement in time error responses. The mean UCE sum plots show no significant increase in the amount of unit control, and for the majority of generating units, there is actually a significant decrease. These improvements are achieved using different calculation schemes for the different operating conditions. For example, the October 17 and July 11 data sets show calculation methods $\# 1$ and $\# 3$ with the greatest decrease in time error and unit control, while the April 4 and July 12 data sets yield the best time error response using calculation method \#3. This suggests that method \#3 gives the better AGC control based on a decline in the accumulated time error and the unit control error.

Although the time error plots for the data sets depicted in this report show only small decreases in the time error accumulation, the improvements are emphasized greatly by the decrease in unit control. Inspection of the bias factor curves for each data set shows an average bias factor that has increased in magnitude only slightly from the base case value of $15 \mathrm{MW} / 0.1 \mathrm{~Hz}$. This small increase, for the most part, results in a large decrease in the amount of unit control required for regulatory purposes. This illustrates that use of a static bias value does not ideally represent the non-linear, variable nature of the system response characteristic. It is this characteristic that the dynamic calculation methods described in Chapter 4 are attempting to model. 


\section{Chapter 6}

\section{Conclusions and Recommendations}

\subsection{Contributions of this Research}

Automatic generation control is a decades oid control process. It is utilized by the electrical power utility's Energy Management System to provide a regulation function for frequency and tie-line power deviations, and to economically allocate generation to meet load demand. AGC has been the topic of much research over the years with the primary aim of improving this regulation function. Since the majority of power systems in North America are interconnected, AGC in an isolated power system is rarely considered as a research topic. This report introduces calculation methods for a dynamic bias factor in a power system without tie-line interconnections, and using computer simulation methods, arrives at an improved AGC process. This process provides a lower time error accumulation that equates to a better frequency regulation. This is accomplished with less secondary unit control than is required with a static bias value.

A computer simulation model of the Newfoundland and Labrador Hydro power system has been developed that enables the off-line study of a dynamic bias factor in the AGC control process. Actual system data, taken from the NLH EMS Dispatcher Training Simulator, has been used to model the system dynamics. The model has been thoroughly 
tested using the actual system frequency, $\mathrm{ACE}$, time error and unit generations for comparison purposes. The simulation results were considered favourable.

The data collected from the computer simulations of the NLH simulation model supports the use of a dynamic bias factor in the AGC calculations. A scheme that utilizes the SRC approximation given by Eq. (4.3) as a sum of the ratios of all on-line generating unit MW generation capacities and speed droop constants, all divided by the scheduled system frequency, yields the most desirable responses (this calculation method has been referred to as dynamic bias factor calculation method $\# 3$ in this report). The calculation is performed when the on-line generator configuration changes. Compared to an hourly or 30-minute bias factor calculation interval, this method requires less calculations per 24-hour period while still providing improved regulation.

The main finding in this report is that with proper tuning of the AGC algorithm will provide improved system regulation. For an isolated power system, this is increasingly important due to the nature of the system. Since the NLH system cannot rely on external power systems in the regulation of frequency and for load supply, the system frequency tends to fluctuate more than it would in an interconnected system. As a result, both time error accumulation and unit control increases. Utilization of the dynamic bias factor proposed in this research will decrease these quantities thus providing improved frequency regulation. 


\subsection{Recommendations}

It is the opinion of the author that an implementation of the proposed dynamic bias factor calculation method will improve the overall system performance, especially the frequency regulation function provided by the automatic generation control process. The implementation will involve coding the calculation method as part of the AGC Processing subfunction in the EMS Automatic Generation Control function. This calculation will be performed when the on-line generator configuration changes. Since the calculation is performed using constant values, that is unit generating capacities and speed droop constants, the calculation would only involve acquiring the status of the unit (on-line/off-line) and no other telemetered data would be required. This would aid in the prevention of erroneous bias values caused by transmission errors.

Testing of the proposed bias factor calculation method on-line can be accomplished using a method proposed by Kennedy, Hoyt and Abell [10]. In this paper, the authors tested their non-linear bias factor on-line by measuring the number of times the ACE exceeded a set of boundary conditions and whether it was determined using the static or dynamic bias factor. The two schemes were alternated every four hours in the AGC function. To avoid inconsistent comparison of the two bias modes, the rotation was shifted by four hours at midnight. This process was continued for several months and the daily ACE totals were plotted showing the static mode minus the dynamic mode. When the subtraction result was positive, the static mode exceeded the ACE boundaries more meaning the dynamic mode provided better regulation. This test method should be sufficient to determine the benefits of the proposed bias factor calculation method. 
With future changes to the NLH power system anticipated in the coming years, particularly with respect to new generation sources to meet an increased load level, the tuning of the AGC algorithm becomes increasingly necessary. Depending on the generation type added to the system, new generation may be available for frequency regulation. Also, the present static bias factor was determined for a system response characteristic that will change when the new load and generation are connected to the grid, especially for the anticipated industrial load that will be part of the Argentia smelter. As discussed in Chapter 2, if the bias value is too large or too small, which will occur when the network configuration changes, regulation will suffer. The result is that the overall system performance would benefit from a properly tuned AGC process. 


\section{Chapter 7}

\section{References}

[1] North American Electric Reliability Council, Princeton, NJ, Control Area Concepts and Obligations, July 1992.

[2] North American Electric Reliability Council, Princeton, NJ, NERC Operating Manual, 1981 (periodically updated).

[3] P. Kundur, Power System Stability and Control, New York: McGraw-Hill, Inc., 1994.

[4] R.K. Green, "Transformed Automatic Generation Control", IEEE Transactions on Power Systems, Vol. 11, No. 4, pp. 1799-1804, November 1996.

[5] IEEE Working Group on Current Operational Problems, "Current Operating Problems associated with Automatic Generation Control", IEEE Transactions on Power Apparatus and Systems, Vol. PAS-98, No. 1, pp. 88-96, Jan/Feb 1979.

[6] T.M. Athay, "Generation Scheduling and Control", Proceedings of the IEEE, Vol. 75, No. 12, pp. 1592-1606, December 1987.

[7] L.S. VanSylck, N. Jaleeli and W.R. Kelley, "Implications of Frequency Control Bias Settings on Interconnected System Operation and Inadvertent Energy Accounting", IEEE Transactions on Power Systems, Vol. 4, No. 2, pp. 712-723, May 1989. 
[8] IEEE Working Group on Current Operational Problems, "Cost Aspects of AGC, Inadvertent Energy and Time Error", IEEE Transactions on Power Systems, Vol. 5, No. 1, pp. 111-118, February 1990.

[9] B. Oni, H. Graham and L. Walker, "Investigation of Nonlinear Tie Line Bias Control of Interconnected Power Systems", IEEE Transactions on Power Apparatus and Systems, Vol. PAS-100, No. 5, pp. 2350-2356, May 1981.

[10] T. Kennedy, S.M. Hoyt and C.F. Abell, "Variable, Non-Linear Tie-Line Frequency Bias for Interconnected Systems Control", IEEE Transactions on Power Systems, Vol. 3, No. 3, pp. 1244-1253, August 1988.

[11] N. Jaleeli, L.S. VanSlyck, D.N. Ewart, L.H. Fink and A.G. Hoffman, "Understanding Automatic Generation Control", IEEE Transactions on Power Systems, Vol. 7, pp. 1106-1122, August 1992.

[12] MATLAB ${ }^{\circledast}$ User's Guide, The MathWork's, Inc., 1992.

[13] SIMULINK ${ }^{\circledast}$ User's Guide, The MathWorks, Inc., 1992.

[14] IEEE Committee Report, "Dynamic Models for Steam and Hydro Turbines in Power Systems Studies", IEEE Transactions on Power Apparatus and Systems, Vol. PAS-92, pp.1904-1915, November/December 1973. 
Appendices 


\title{
Appendix A
}

Newfoundland and Labrador Hydro

\author{
Generating Units
}


Table A.1 Newfoundland and Labrador Hydro Generating Units

\begin{tabular}{|c|c|c|c|c|c|}
\hline $\begin{array}{c}\text { Unit } \\
\#\end{array}$ & $\begin{array}{c}\text { Unit } \\
\text { Abbrev. }\end{array}$ & Unit Name & $\begin{array}{l}\text { Unit } \\
\text { Type }^{1}\end{array}$ & $\begin{array}{c}\text { Generating } \\
\text { Capacity (MW) }\end{array}$ & $\begin{array}{l}\text { AGC? } \\
(\mathbf{Y} / \mathbf{N})\end{array}$ \\
\hline 1 & BDE1 & Bay D'Espoir Unit \#1 & $\mathrm{H}$ & 74 & $\mathrm{Y}$ \\
\hline 2 & BDE2 & Bay D'Espoir Unit \#2 & $\mathrm{H}$ & 76 & $\mathrm{Y}$ \\
\hline 3 & BDE3 & Bay D'Espoir Unit \#3 & $\mathrm{H}$ & 78 & $\mathrm{Y}$ \\
\hline 4 & $\overline{\mathrm{BDE} 4}$ & Bay D'Espoir Unit \#4 & $\mathrm{H}$ & 76 & $\mathrm{Y}$ \\
\hline 5 & BDE5 & Bay D'Espoir Unit \#5 & $\mathrm{H}$ & 74 & $\mathrm{Y}$ \\
\hline 6 & BDE6 & Bay D'Espoir Unit \#6 & $\mathrm{H}$ & 74 & $\mathrm{Y}$ \\
\hline 7 & BDE7 & Bay D'Espoir Unit \#7 & $\mathrm{H}$ & 160 & $\mathrm{Y}$ \\
\hline 8 & CAT1 & Cat Arm Unit \#1 & $\mathrm{H}$ & 67 & $\mathrm{Y}$ \\
\hline 9 & CAT2 & Cat Arm Unit \#2 & $\mathrm{H}$ & 67 & $\mathrm{Y}$ \\
\hline 10 & HLK & Hinds Lake & $\mathrm{H}$ & 80 & $\mathrm{Y}$ \\
\hline 11 & USL & Upper Salmon & $\mathrm{H}$ & 90 & $\mathrm{Y}$ \\
\hline 12 & HRD1 & Holyrood Unit \#1 & $T$ & 175 & $\mathrm{~N}$ \\
\hline 13 & HRD2 & Holyrood Unit \#2 & $\mathrm{T}$ & 175 & $\mathrm{~N}$ \\
\hline 14 & HRD3 & Holyrood Unit \#3 & $T$ & 150 & $\mathrm{~N}$ \\
\hline 15 & HWD & Hardwoods Gas Turbine & $\mathrm{G}$ & 25 & $\mathrm{~N}$ \\
\hline 16 & STV & Stephenville Gas Turbine & $\mathrm{G}$ & 52 & $\mathbf{N}$ \\
\hline 17 & PRV & Paradise River & $\mathrm{H}$ & 9 & $\mathrm{~N}$ \\
\hline
\end{tabular}

${ }^{1}$ Hydro, Thermal, Gas Turbine types 


\section{Appendix B}

Simulation Programs and Parameters 


\section{Sample MATLAB Simulation Program}

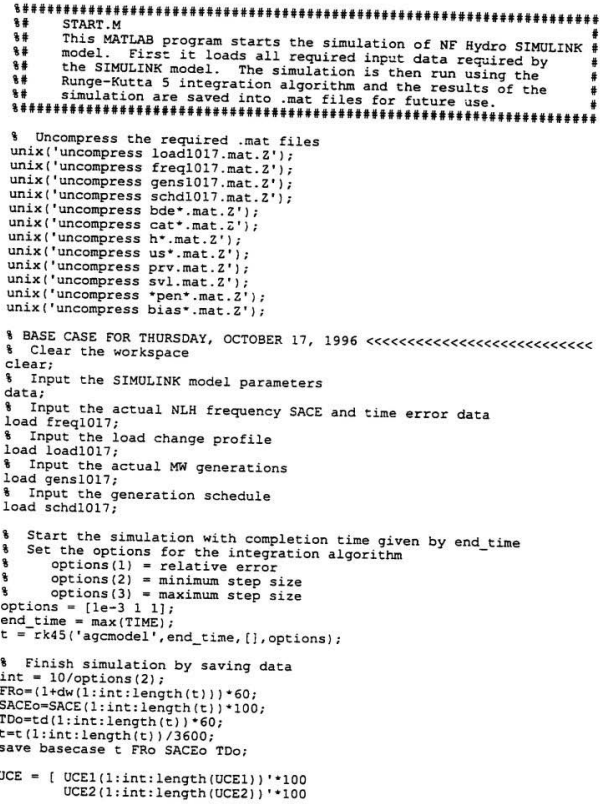



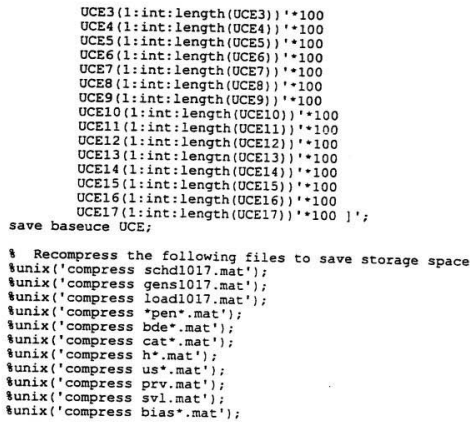


\section{Simulation Parameters}

\section{Integration Parameters}

Integration Method: Runge-Kutta fifth order

Simulation Length, tfinal: 86400 seconds ( 24 hours)

Initial Conditions, $x 0$ : [ ] (no additional initial conditions specified)

Relative Error, options(1): 1e-3

Minimum Step Size, options(2): 1 second

Maximum Step Size, options(3): 1 second

\section{System Parameters}

Nominal System Frequency, $f_{\text {sys }}: 60 \mathrm{~Hz}$

MVA Base, $\mathrm{S}_{\text {base }}: 100 \mathrm{MVA}$

AGC Sample Rate: 4 seconds

Static Bias Factor, B: $15 \mathrm{MW} / 0.1 \mathrm{~Hz}$

Load Damping Constant, D: $1 \%$ 


\section{Bibliography}

Bergen, A.R. (1986). Power System Analysis, Prentice-Hall, Inc., Englewood Cliffs, N.J., 529 p.

Bose, A., and Atiyyah, I. (1980). "Regulation Error in Load Frequency Control," IEEE Transactions on Power Apparatus and Systems, Vol. PAS-99, No. 2, pp. 650-657.

Carpentier, J. (1985). "To be or not to be modern' that is the question for automatic generation control (point of view of a utility engineer)," Electrical Power \& Energy Systems, Vol. 7, No. 2, pp. 81-91.

Dunlop, R.D., and Ewar, D.N. (1975). "System Requirements for Dynarnic Performance and Response of Generating Units," IEEE Transactions on Power Apparatus and Systems, Vol. PAS-94, No. 3, pp. 838-849.

Elgerd, O.1., and Fosha, Jr., C.E. (1970). "Optimum Megawatt-Frequency Control of Multiarea Electric Energy Systems," IEEE Transactions on Power Apparatus and Systems, Vol. PAS-89, No. 4, pp. 556-563.

Fosha, Jr., C.E., and Elgerd, O.I. (1970). "The Megawatt-Frequency Control Problem: A New Approach Via Optimal Control Theory," IEEE Transactions on Power Apparatus and Systems, Vol. PAS-89, No. 4, pp. 563-577.

Hicks, G.V. (1995). "AGC Simulation of Interconnected Power Systems," Course Project Report, Memorial University of Newfoundland, St. John's, Newfoundland, Canada, 46 p. 
IEEE Standards Committee (1970). "IEEE Standard Definitions of Terms for Automatic Generation Control on Electric Power Systems," IEEE Transactions on Power Apparatus and Systems, Vol. PAS-89, No. 6, pp. 1356-1363.

Liu, K., et al. (1996). "Comparison of Very Short-Term Load Forecasting Techniques," IEEE Transactions on Power Systems, Vol. 11, No. 2, pp. 877-882.

Ross, H.B., et al. (1994). "An AGC Implementation for System Islanding and Restoration Conditions," IEEE Transactions on Power Systems, Vol. 9, No. 3, pp. 1399-1405. Schulte, R.P. (1996). "An Automatic Gencration Control Modification for Present Demands on Interconnected Power Systems," IEEE Transactions on Power Systems, Vol. 11, No. 3, pp.1286-1294.

Taylor, C.W., and Cresap, R.L. (1976). "Real-Time Power System Simulation for Automatic Generation Control," IEEE Transactions on Power Apparatus and Systems, Vol. PAS-95, No. 1, pp. 375-384.

VanSlyck, L.S., Jaleeli, N., and Kelley, W.R. (1989). "A Comprehensive Shakedown of an Automatic Generation Control Process," IEEE Transactions on Power Systems, Vol. 4, No. 2, pp. 771-781.

Vournas, C.D., et al. (1989). "A Flexible AGC Algorithm for the Hellenic Interconnected System," IEEE Transactions on Power Systems, Vol. 4, No. 1, pp.61-68. 


.

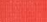

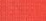

1.

$(+4)+4=$

15ivis

+50 (2)

(x)

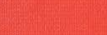

